OPEN ACCESS

Edited by:

Georgia Fousteri,

San Raffaele Hospital (IRCCS), Italy

Reviewed by:

Hu Zeng,

Mayo Clinic, United States

Thomas Ciucci,

National Cancer Institute (NCl),

United States

${ }^{*}$ Correspondence:

George Kassiotis

george.kassiotis@crick.ac.uk

Specialty section: This article was submitted to T Cell Biology,

a section of the journal

Frontiers in Immunology

Received: 28 March 2018

Accepted: 18 May 2018

Published: 05 June 2018

Citation:

Danelli L, Donnarumma T and Kassiotis G (2018) Correlates

of Follicular Helper Bias in

the CD4 T Cell Response

to a Retroviral Antigen.

Front. Immunol. 9:1260.

doi: 10.3389/fimmu.2018.01260

\section{Correlates of Follicular Helper Bias in the CD4 T Cell Response to a Retroviral Antigen}

\author{
Luca Danelli ${ }^{1}$, Tiziano Donnarumma ${ }^{1}$ and George Kassiotis ${ }^{1,2 *}$ \\ ${ }^{1}$ Retroviral Immunology, The Francis Crick Institute, London, United Kingdom, ${ }^{2}$ Department of Medicine, Faculty of Medicine, \\ Imperial College London, London, United Kingdom
}

CD4 ${ }^{+} \mathrm{T}$ cell differentiation is influenced by a plethora of intrinsic and extrinsic factors, providing the immune system with the ability to tailor its response according to specific stimuli. Indeed, different classes of pathogens may induce a distinct balance of CD4 ${ }^{+} T$ cell differentiation programmes. Here, we report an uncommonly strong bias toward follicular helper (Tfh) differentiation of CD4 ${ }^{+} \mathrm{T}$ cells reactive with a retroviral envelope glycoprotein model antigen, presented in its natural context during retroviral infection. Conversely, the response to the same antigen, presented in different immunization regimens, elicited a response typically balanced between Tfh and T helper 1 cells. Comprehensive quantitation of variables known to influence Tfh differentiation revealed the closest correlation with the strength of T cell receptor (TCR) signaling, leading to PD-1 expression, but not with surface TCR downregulation, irrespective of TCR clonotypic avidity. In contrast, strong TCR signaling leading to TCR downregulation and induction of LAG3 expression in high TCR avidity clonotypes restrained $\mathrm{CD}^{+}{ }^{+} \mathrm{T}$ cell commitment and further differentiation. Finally, stunted Th1 differentiation, correlating with limited IL-2 availability in retroviral infection, provided permissive conditions for Tfh development, suggesting that Tfh differentiation is the default program of envelope-reactive CD4+ $T$ cells.

Keywords: CD4 T cell response, follicular helper T cells, retroviral infection, CD4 T cell differentiation, TH1 T cells, vaccine vectors and adjuvants

\section{INTRODUCTION}

Several divergent and often competing programmes of $\mathrm{CD}^{+} \mathrm{T}$ cell differentiation are now well recognized, leading to the development of distinct functional subsets, including $\mathrm{T}$ helper (Th) 1, 2, or 17 cells, follicular helper (Th) cells, and regulatory $\mathrm{T}$ (Treg) cells (1-5). The relative balance of $\mathrm{CD} 4^{+} \mathrm{T}$ cell differentiation to one or more of these functional subsets largely depends on a multitude of $\mathrm{T}$ cell-extrinsic factors, with the cytokine milieu naïve $\mathrm{T}$ cells encounter during the priming phase playing a major role (1-5). However, $\mathrm{CD} 4^{+} \mathrm{T}$ cell differentiation can also be shaped by $\mathrm{T}$ cell-intrinsic properties, such as the relative affinity of the T cell receptor (TCR), favoring development of particu lar subsets (6-8). The combined effect of such T cell-extrinsic and T cell-intrinsic factors can result in considerable diversity of functional responses, allowing adaptive immunity to modify its response according to the nature of the antigenic stimulus.

Acute viral infections typically induce a $\mathrm{CD} 4^{+} \mathrm{T}$ cell response that is almost exclusively composed of Tfh and Th1 cells, in approximately equal proportion. Indeed, the ratio of Tfh to Th1 cells in the $\mathrm{CD} 4^{+} \mathrm{T}$ cell response to acute lymphocytic choriomeningitis virus (LCMV) has been amply reported 
close to 1 and 2 for LCMV Armstrong (9-14) and clone 13 (Cl13) (15-19), respectively, and similar results were also reported for influenza A virus infection (20-23).

Several well-defined factors have been demonstrated to influence the balance of Th1 and Tfh cells in response to viruses, as well as other challenges. One of these is the availability of IL-2, determined both by the rate of production by effector $\mathrm{CD} 4^{+}$ $\mathrm{T}$ cells and the rate of consumption by Treg cells or dendritic cells $(20,24-26)$. IL-2 has been reported to negatively affect Tfh differentiation, in favor of Th1 differentiation (20, 24-26). The balance of Th1 and Tfh differentiations in response to infection with viruses, as well as other classes of pathogens, is also strongly influenced by the nature of the dominant antigen-presenting cell (APC) type $(2,3,5,6)$. For example, antigen presentation by $\mathrm{B}$ cells is considered critical for consolidating Tfh differentiation, whereas presentation by macrophages is thought to promote Th1 differentiation $(2,3,5,6)$.

How $\mathrm{T}$ cells integrate the multitude of intrinsic and extrinsic factors regulating the balance of their differentiation is not currently completely understood. It is possible that these factors do not operate independently, but are linked at the level of APC-T cell interaction. Indeed, the type of dominant APC determines the cytokine milieu (e.g., IL-12 production or IL-2 consumption) $(20,24-26)$, the provision of costimulatory signals (e.g., ICOS-L) $(5,27)$, and the TCR signal strength, given that APC types differ in the potency of stimulation.

We studied the $\mathrm{CD}^{+} \mathrm{T}$ cell response to model retroviral antigen from the gp70 envelope glycoprotein of the Friend murine leukemia virus (F-MLV) $(28,29)$, to assess the relative contribution of individual intrinsic and extrinsic factors, previously linked to the balance of Th1 and Tfh differentiations. Here, we report an atypically strong bias toward Tfh differentiation in response to this retroviral antigen, when presented during natural infection, and describe the variables of the immune response that determine the balance of Th1 and Tfh differentiations in this setting.

\section{MATERIALS AND METHODS}

\section{Mice}

Inbred C57BL/6 (B6) and CD45.1+ congenic B6 (B6.SJL-Ptprca Pep3b/BoyJ) mice were originally obtained from The Jackson Laboratory (Bar Harbor, ME, USA). TCR $\beta$-transgenic EF4.1 mice (30), Nur77-GFP transgenic mice (31), B cell receptordeficient $\left(\mathrm{Ighm}^{-/-}\right)$(32), Tcra-deficient $\left(\mathrm{Tcra}^{-/}\right)$(33), Rag1-deficient $\left(\right.$ Rag1 $\left.^{-/-}\right)$mice (34), and Rag2-deficient $\left(\right.$Rag $\left.^{-/-}\right)$mice (35) were on the B6 genetic background and were maintained at the Francis Crick Institute's animal facilities. All animal experiments were approved by the ethical committee of the Francis Crick Institute and conducted according to local guidelines and UK Home Office regulations under the Animals Scientific Procedures Act 1986 (ASPA).

\section{CD4+ ${ }^{+}$Cell Adoptive Transfer}

Single-cell suspensions were prepared from the spleens of donor CD $45.1^{+}$or CD $45.2^{+}$TCR $\beta$-transgenic EF4.1 mice or CD 45.2 $2^{+}$ Nur77-GFP EF4.1 doubly transgenic mice, and $\mathrm{CD}^{+}{ }^{+} \mathrm{T}$ cells were enriched using an immunomagnetic positive selection kit (StemCell Technologies, Vancouver, BC, Canada), at $>90 \%$ purity. Donor transgenic CD $4^{+} \mathrm{T}$ cells $\left(1 \times 10^{6}\right.$ per recipient $)$ were injected into recipient mice intravenously.

\section{Retroviral Infection and Immunization}

The Friend virus (FV) used in this study was a retroviral complex of a replication-competent B-tropic F-MLV (F-MLV-B) and a replication-defective spleen focus-forming virus (SFFV). Stocks were prepared as previously described (36). Mice were injected intravenously with $0.1 \mathrm{~mL}$ PBS containing 50 (low dose), 1,000 (intermediate dose), or 5,000 (high dose) spleen focus-forming

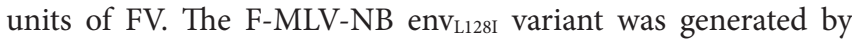
mutagenesis of the respective codon (CTC $\rightarrow$ ATT) in plasmid pLRB302, containing the complete NB-tropic F-MLV clone FB29. The resulting plasmid was then transfected into Mus dunni fibroblast cells (M. dunni cells; CRL-2017). Stocks of F-MLV-B, F-MLV-NB env ${ }_{\mathrm{L} 128 \mathrm{I}}$, or F-MLV-N helper virus were grown in M. dunni cells. Mice received an inoculum of $\sim 10^{4}$ infectious units of helper virus by intravenous injection. Ad5.pIX-gp70 stocks were prepared at a titer of $9 \times 10^{9}$ viral genomes per milliliter by infection of $293 \mathrm{~A}$ cells as previously described (37). Approximately $5 \times 10^{8}$ Ad5.pIX-gp70 viral genomes per mouse were administered intravenously. Immunization with FBL-3 tumor cells was carried out by intravenous injection of $1.5 \times 10^{6}$ FBL-3 cells (38). For peptide immunization, mice received an intraperitoneal injection of a total of $12.5 \mathrm{nmol}$ of synthetic env 122-141 peptide mixed in Sigma Adjuvant System (Sigma-Aldrich, St. Louis, MO, USA). Where indicated, recipient mice also received blocking antibodies against PD-1 (10 mg/kg, clone RMP1-14) and LAG3 (10 mg/kg, clone C9B7W) (both from BioXCell, West Lebanon, NH, USA), injected intraperitoneally on days $0,1,3$, and 5 post FV infection.

\section{Antibodies and Flow Cytometry}

Spleen single-cell suspensions were stained for $20 \mathrm{~min}$ at room temperature or at $4^{\circ} \mathrm{C}$ with directly conjugated antibodies to surface markers. For detection of intracellular antigens, subsequent to surface staining, cells were fixed and permeabilized using the Foxp3/Transcription Factor Staining Buffer Set (Thermo Fisher Scientific, Waltham, MA, USA) according to the manufacturer's instructions. They were then incubated for $45 \mathrm{~min}$ at room temperature with directly conjugated antibodies to intracellular antigens. Zombie UV Fixable Viability Kit (BioLegend, San Diego, CA, USA) was used to label and exclude dead cells from analysis. The following anti-mouse antibodies were used: BV785- or BV711-anti-CD4 (clone GK1.5), PE/Cy7-anti-CD45.1 (clone A20), PE/Cy7anti-CD279 (PD-1, clone 29F.1A12), BV785-anti-CD150 (SLAM, clone TC15-12F12.2) (from BioLegend); V500-anti-CD44 (clone IM7), BV421- or PerCPCy5.5-anti-CD162 (PSGL1, clone 2PH1), BV421-anti-Ly6C (clone AL-21), PE-anti-Bcl6 (clone K112-91), FITC-anti-V $\alpha 2$ (clone B20.1) (from BD Biosciences, San Jose, CA, USA); PE-anti-CD25 (clone PC61.5), PE-Cyanine7-antiCD45R (B220, clone RA3-6B2), APC-eFluor-780-anti-CD45.2 (clone 104), eFluor450-anti-CD45.1 (clone A20), PE-anti-CD223 (LAG3, clone eBioC9B7W), APC-anti-Ter119 (clone TER-119), APC-anti-V $\alpha 2$ (clone B20.1), FITC- or APC-anti-TCR $\beta$ (clone H57-597) (from Thermo Fisher Scientific, Waltham, MA, USA); Alexa(R)488- or Alexa(R)647-anti-TCF1 (clone C63D9) (from 
Cell Signaling Technology, Danvers, MA, USA). For CXCR5 staining, splenocytes were incubated with biotin rat anti-mouse CXCR5 antibody (clone $2 \mathrm{G} 8, \mathrm{BD}$ Biosciences) at $37^{\circ} \mathrm{C}$ for $25 \mathrm{~min}$, followed by incubation with APC- or PE-streptavidin (BioLegend) for $20 \mathrm{~min}$ at room temperature. FV-infected cells were detected by using surface staining for the glycosylated product of the viral gag gene (Glyco-Gag), using the matrix (MA)-specific monoclonal antibody 34 (mouse IgG2b), followed by an FITC-anti-mouse IgG2b secondary reagent (clone 12-3 from BD). Multi-color cytometry was performed on LSRFortessa flow cytometers (from BD Biosciences) and analyzed with FlowJo v10.1 (Tree Star Inc., Ashland, OR, USA).

\section{Fluorescence Microscopy}

Frozen OCT (Dako)-embedded spleen sections were fixed in cold acetone, stained with fluorescein labeled peanut agglutinin (PNA, Vector Laboratories), and with directly conjugated antibodies against anti-mouse/human B220 (clone RA3-6B2, AlexaFluor 594, BioLegend) and anti-mouse CD45.1 (clone A20, Alexa Fluor 647, BioLegend). Stained sections were mounted in fluorescent mounting medium (Dako) and viewed with an Olympus IX83 inverted microscope system (Olympus Corporation, Shinjuku, Tokyo, Japan).

\section{Analysis of Single-Cell RNA-Sequencing Data}

Gene transcription in env-reactive $\mathrm{CD}^{+} \mathrm{T}$ cells was assessed using publicly available single-cell RNA-sequencing data (European Nucleotide Archive accession number PRJEB14043) as previously described (39). These included the transcriptional profiles of single env-reactive donor $\mathrm{CD} 4^{+} \mathrm{T}$ cells isolated from the spleens of wild-type (WT) recipients infected with FV or immunized with Ad5.pIX-gp70, 7 days previously. They also included the transcriptional profiles of single env-reactive donor EF4.1 CD4 ${ }^{+}$ $\mathrm{T}$ cells that carried a WT Bcl6 allele $\left(B c l 6^{w t}\right)$ or a conditional $B c l 6$ allele $\left(B c l 6^{f}\right)$, purified from the spleens of WT recipient mice, 7 days after FV infection. Expression values were analyzed using the Qlucore Omics Explorer 3.3 (Qlucore, Lund, Sweden), and pathway analyses were performed using The Database for Annotation, Visualization and Integrated Discovery v6.8 (https:// david.ncifcrf.gov/home.jsp).

\section{Cytokine Gene Transcription and Protein Production}

Serum levels of IL-2 were measured on a Luminex system (BioPlex 100) using the mouse cytokine kits (Bioplex Mouse cytokine group II and Bioplex Mouse Cytokine Standard; Bio-Rad Laboratories, Hercules, CA, USA) following the manufacturer's instructions, as previously described $(30,40)$. Transcription of the indicted cytokine genes in env-reactive $\mathrm{CD} 4^{+} \mathrm{T}$ cells was assessed using publicly available single-cell RNA-sequencing data, as described above.

\section{Statistical Analyses}

Statistical comparisons were made using SigmaPlot 13.0 (Systat Software Inc., Germany) or GraphPad Prism 7 (GraphPad
Software, La Jolla, CA, USA). Parametric comparisons of normally distributed values that satisfied the variance criteria were made by unpaired Student's $t$-tests or One Way Analysis of variance (ANOVA) tests. Data that did not pass the variance test were compared with non-parametric two-tailed Mann-Whitney Rank Sum tests or ANOVA on Ranks tests. $p$ Values are indicated by asterisks as follows: ${ }^{*} p<0.05 ;{ }^{* *} p<0.005$; ${ }^{* *} p<0.0005$. Hierarchical clustering, principal component analysis, and heatmap production were performed with Qlucore Omics Explorer 3.3 (Qlucore).

\section{RESULTS}

\section{The CD4 ${ }^{+}$T Cell Response to F-MLV Env Is Heavily Dominated by Tfh Cells}

To study $\mathrm{CD}^{+}$effector $\mathrm{T}$ cell development, we employed a well-described adoptive transfer system, where EF4.1 TCR $\beta$ transgenic $\mathrm{CD}^{+} \mathrm{T}$ cells, reactive with the dominant $\mathrm{H} 2-\mathrm{A}^{\mathrm{b}}$ restricted env ${ }_{122-141}$ epitope within the F-MLV gp70 glycoprotein, were transferred into WT B6 recipients $(37,41)$. Transferred $\mathrm{T}$ cells were primed in recipient mice by infection with $\mathrm{FV}$, a retroviral complex of F-MLV and SFFV that causes chronic infection in $\mathrm{B} 6$ mice $(28,29)$.

As previously reported $(41,42)$, a considerable proportion $(\sim 50 \%)$ of env-reactive EF4.1 CD $4^{+} \mathrm{T}$ cells developed a PD- $1^{\text {high }}$ $\mathrm{CXCR}^{+}$phenotype consistent with Tfh cells (Figure 1A). Further detailed phenotypic characterization confirmed the Tfh profile of these cells as CXCR5 ${ }^{+}$PD- ${ }^{\text {high }} \mathrm{Bcl6}^{+} \mathrm{PSGL1}^{-} \mathrm{Ly}^{-} \mathrm{C}^{-} \mathrm{SLAM}^{\text {low }}$ (Figure 1B). Consistent with their phenotype, a large proportion of donor $\mathrm{CD}^{+} \mathrm{T}$ cells localized within $\mathrm{B}$ cell follicles or germinal centers in the spleens of recipient mice (Figure 1C), further supporting strong Tfh differentiation of env-reactive EF4.1 CD4 ${ }^{+}$ $\mathrm{T}$ cells.

Notable, however, were the relative paucity $(\sim 10 \%)$ of envreactive EF4.1 $\mathrm{CD}^{+}{ }^{+} \mathrm{T}$ cells with a Th1 phenotype (PSGL1 ${ }^{+}$ PD- $1^{+}$SLAM $^{+}$CXCR5 $^{-} \mathrm{Bcl6}^{-}$Ly6C $^{-}$) (43) and the presence of a sizable population $(\sim 35 \%)$ of cells that lacked markers of $\mathrm{Tfh}$ or Th1 commitment (PSGL1- SLAM- CXCR5 ${ }^{-}$) (Figures 1A,B). The latter population, referred here as Th0 to denote their uncommitted state (44), retained TCF-1 expression and expressed low levels of Bcl6 (Figure 1B).

As antigen availability can greatly influence $\mathrm{CD}^{+} \mathrm{T}$ cell differentiation, we compared the efficiency of Tfh development in response to different FV loads (Figure 1D). Surprisingly, the proportion of seemingly uncommitted Th0 cells correlated inversely with levels of FV infection, both in terms of absolute numbers and proportion within env-reactive donor $\mathrm{CD} 4^{+} \mathrm{T}$ cells (Figures 1B,E). Indeed, whereas the highest dose of FV primed increased absolute numbers of all three EF4.1 CD4 ${ }^{+} \mathrm{T}$ cell subsets, Th0 cells exhibited the highest increase (Figure 1E). In contrast, the lowest dose of FV elicited considerable reduced numbers of Th0 and Th1 cells, while favoring development of Tfh cells, which now comprised the overwhelming majority (Figure 1E).

Thus, FV infection induces primarily a Tfh phenotype in env-reactive EF4.1 CD4 ${ }^{+} \mathrm{T}$ cells and, to a much lesser extent, a Th1 phenotype (Figure 1E), whereas Th2, Th17, Treg, or CTL 


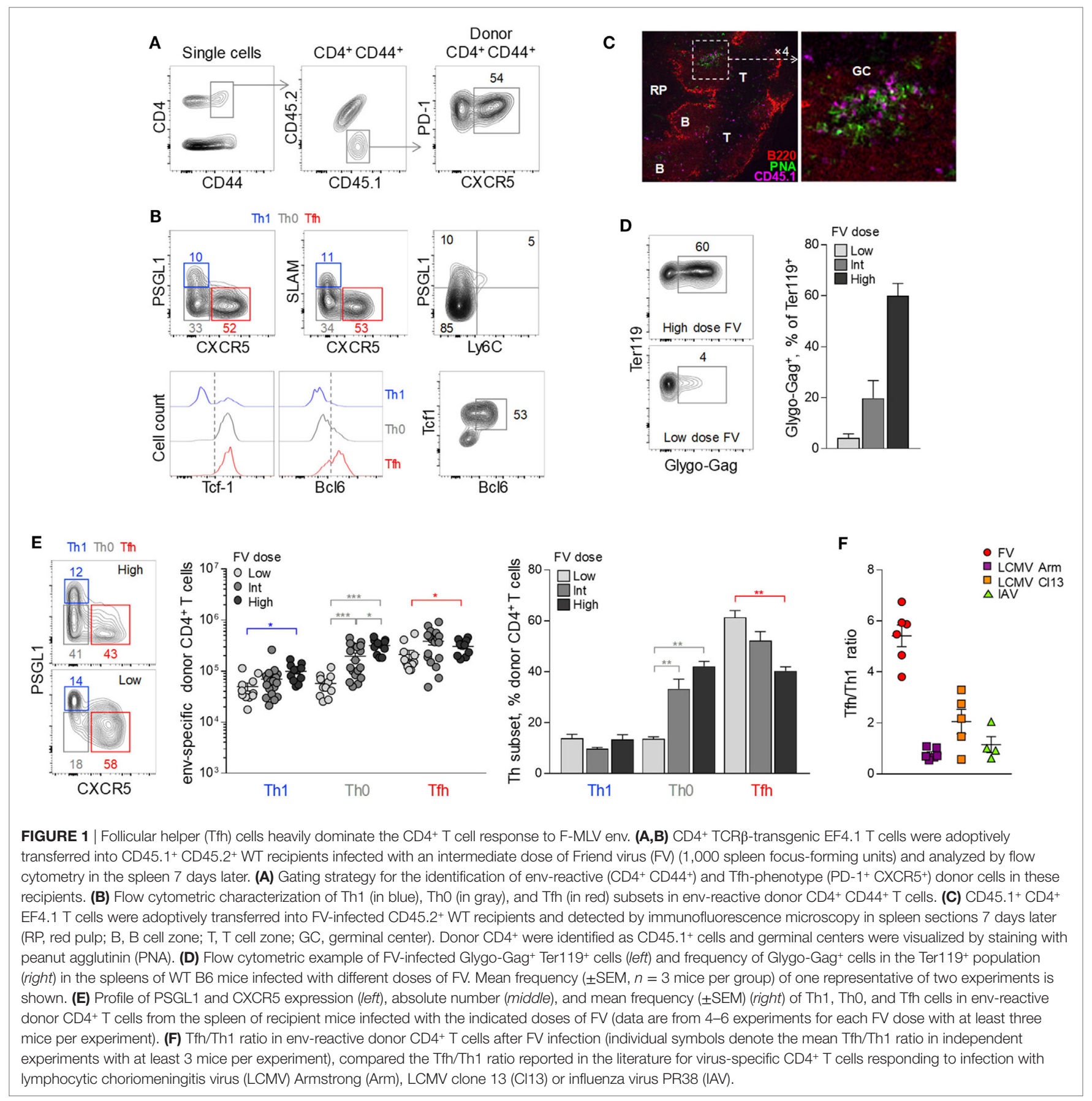

differentiation is not typically observed $(37,39,42)$. This skewing in favor of Tfh differentiation was much more pronounced in FV infection, where there are on average 5.2 times more Tfh than Th1 cells, than in other acute viral infections, where this ratio is consistently reported to be closer to 1 (9-23) (Figure 1F).

\section{Distinguishable Transcriptional Activity of Uncommitted Th0 Cells}

The strong bias in Tfh development following FV infection suggested that the seemingly uncommitted Th0 cells were primed env-reactive $\mathrm{CD} 4^{+} \mathrm{T}$ cell that had not successfully completed the program of Tfh differentiation. To better place them in the spectrum of Th differentiation, we compared the transcriptional profiles of Th0 cells using single-cell RNA-sequencing data obtained with env-specific EF4.1 $\mathrm{CD}^{+} \mathrm{T}$ cells primed by FV or a replication-defective human adenovirus serotype 5 vector expressing the F-MLV gp70 glycoprotein (Ad5.pIX-gp70) (39). Th1, Tfh, and Th0 cells were defined here according to their expression of Cxcr5 and Selplg (the gene encoding PSGL1). We first selected the top 204 genes, whose expression best differentiated Th1 and Tfh cells ( $\geq 2$-fold change, $p \leq 0.05$ ) (Figure $2 \mathrm{~A}$ ). 


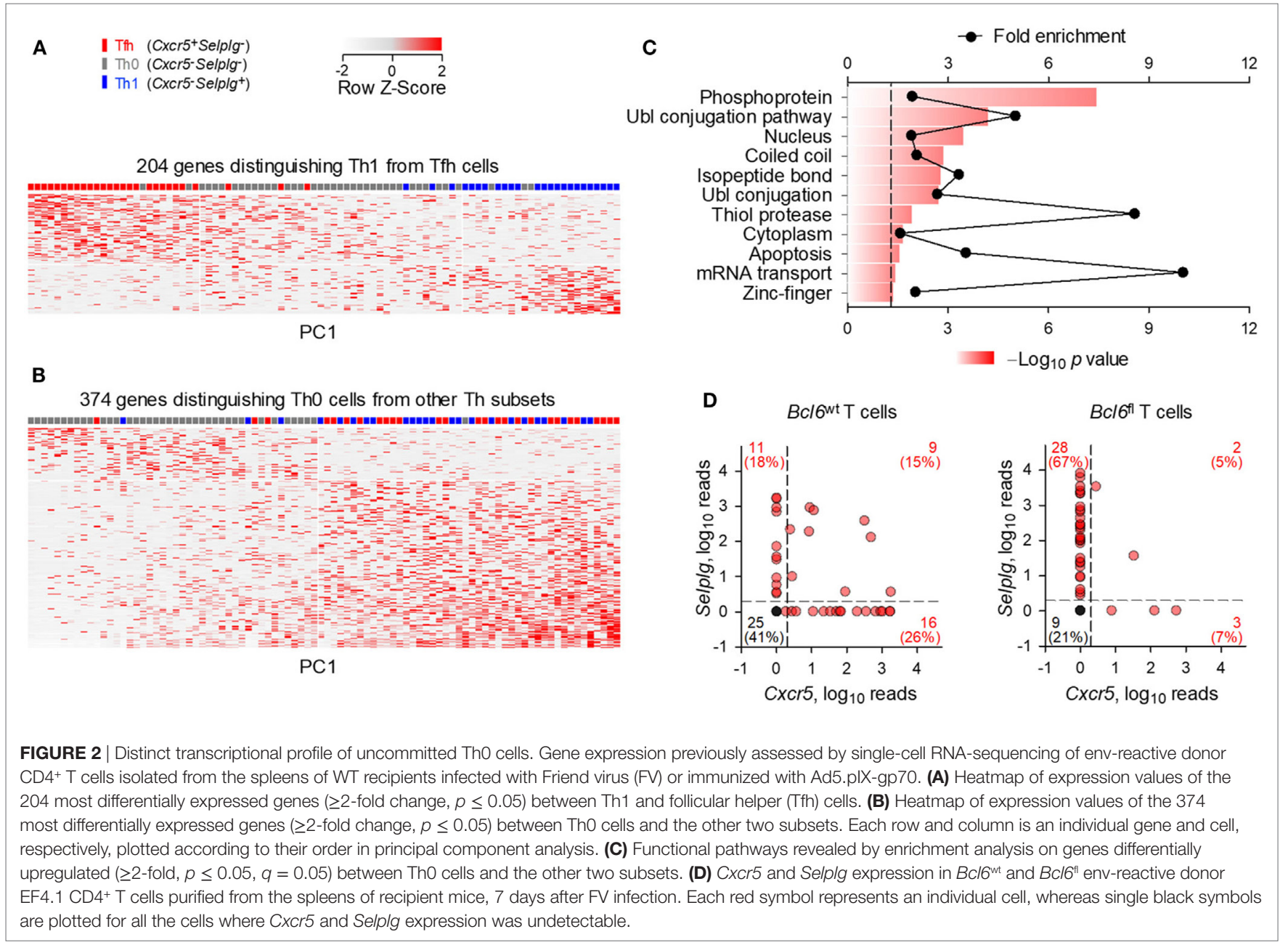

Transcription of these genes in Th0 cells showed a profile that was intermediate between the Th1 and Tfh extremes (Figure 2A), consistent with their unpolarized phenotype. Direct comparison between Th0 cells and the other two subsets revealed an extensive set of genes that were differentially expressed ( $\geq 2$-fold change, $p \leq 0.05)$, the majority of which were absent from Th0 cells (Figure 2B; Table S1 in Supplementary Material). Specific to Th0 cells was expression of 88 genes (Table S1 in Supplementary Material), involved in active metabolic pathways (Figure 2C), indicating a highly activated phenotype of Th0 cells, despite incomplete differentiation.

To further probe any subset commitment of Th0 cells, albeit incomplete, we examined their dependency on Bcl6 expression. This was achieved by using single-cell RNA-sequencing data obtained with env-specific EF4.1 CD4 ${ }^{+}$T cells that carried a WT $B c l 6$ allele $\left(B c l 6^{w t}\right)$ or a conditional $B c l 6$ allele $\left(B c l 6^{f}\right)$ that was deleted by Cre-mediated recombination upon $\mathrm{T}$ cell activation (39). When primed by FV in WT hosts, $41 \%$ (25/61) of Bcl6 ${ }^{w t}$ EF4.1 CD4 ${ }^{+} \mathrm{T}$ cells displayed a Th0 phenotype (Cxcr5 $5^{-}$Selplg $\left.^{-}\right)$, whereas this proportion was reduced to $21 \%$ (9/42) in Bcl6 $6^{f l} \mathrm{EF} 4.1$ $\mathrm{CD}^{+} \mathrm{T}$ cells (Figure 2D), despite comparable numerical priming of both types of T cell under these conditions (39). Together, these data suggested that at least a proportion of Th0 cells may have initiated but not completed Tfh differentiation, particularly in conditions of high viral loads.

\section{Inhibitory Receptors Restrain Full Tfh Maturation in Response to FV Infection}

To further probe how FV loads might influence Tfh differentiation of env-reactive EF4.1 CD4 ${ }^{+}$T cells, we examined the potential effect of inhibitory receptors. At the peak of their response to FV infection, env-reactive EF4.1 CD4 ${ }^{+} \mathrm{T}$ cells have been previously shown to express high levels of multiple inhibitory receptors, including PD-1 and LAG3 (39). Analysis of the earliest time-points at which donor $\mathrm{CD}^{+} \mathrm{T}$ cell expansion can be reliably demonstrated (Figure 3A) revealed that PD-1 and LAG3 expression reached near maximum levels already by day 4 post FV infection (Figure 3B).

Also comparable between days 4 and 7 , post infection was the relative ratio of Tfh and Th1 cells in env-reactive EF4.1 $\mathrm{CD}^{+}$ $\mathrm{T}$ cells (Figure $3 \mathrm{C}$ ), in agreement with commitment to Tfh or Th1 differentiation at this early time-point (45). Given that proliferation of donor $\mathrm{CD} 4^{+} \mathrm{T}$ cells is atypically slowing down between days 4 and 7 post FV infection (37), we reasoned that the early induction of inhibitory receptors during FV infection might restrict further differentiation. Consistent with this notion, 


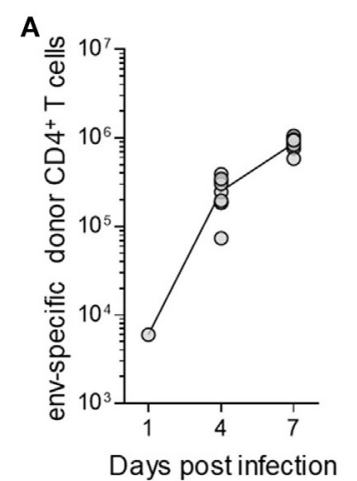

D
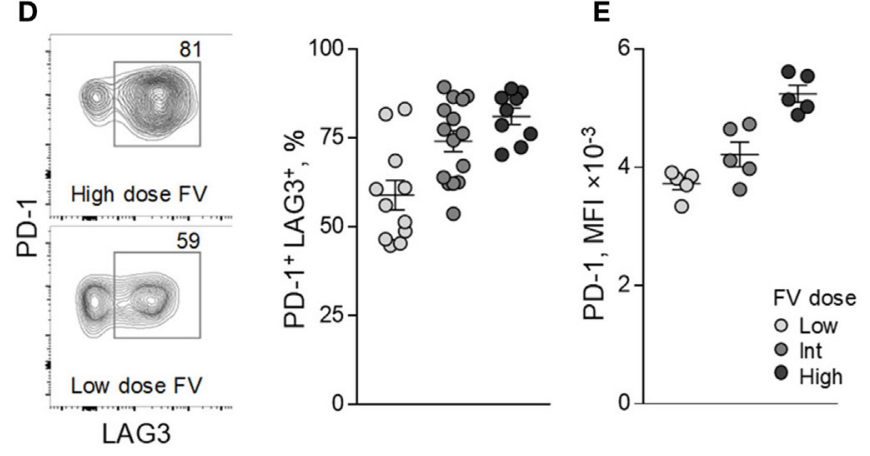

G
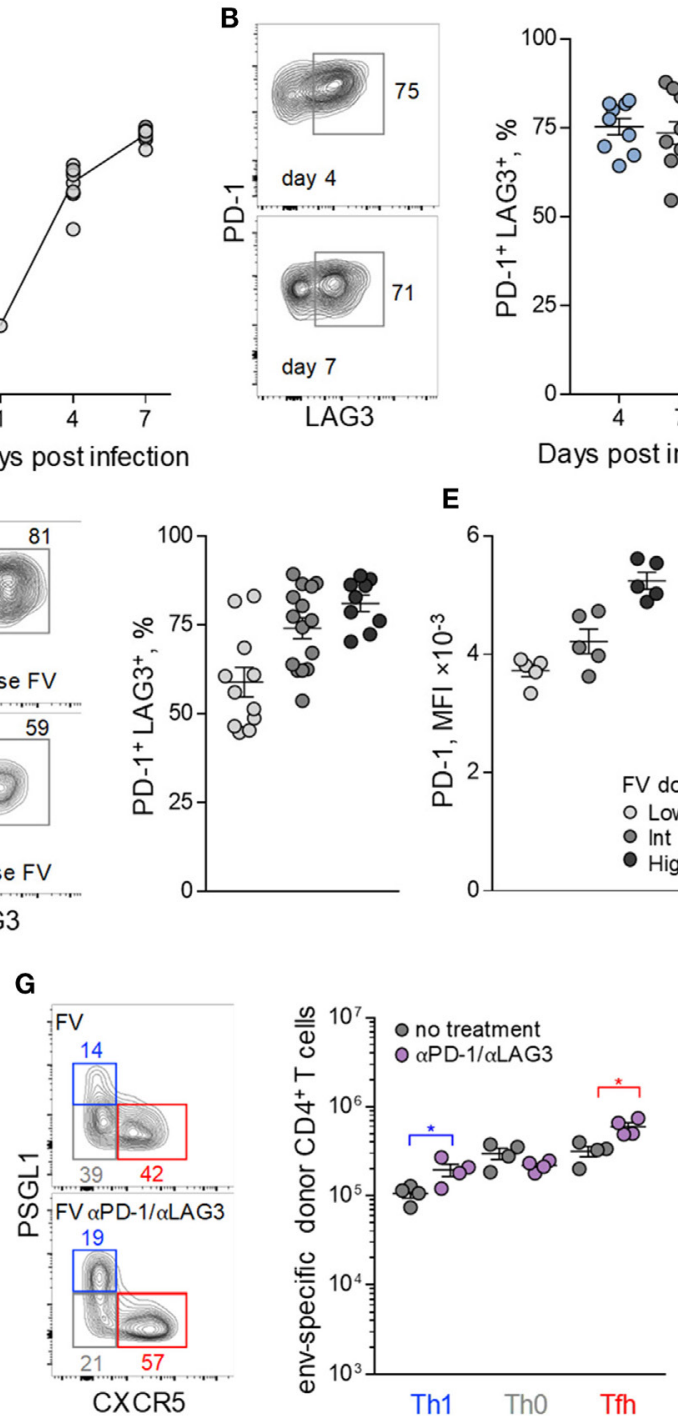
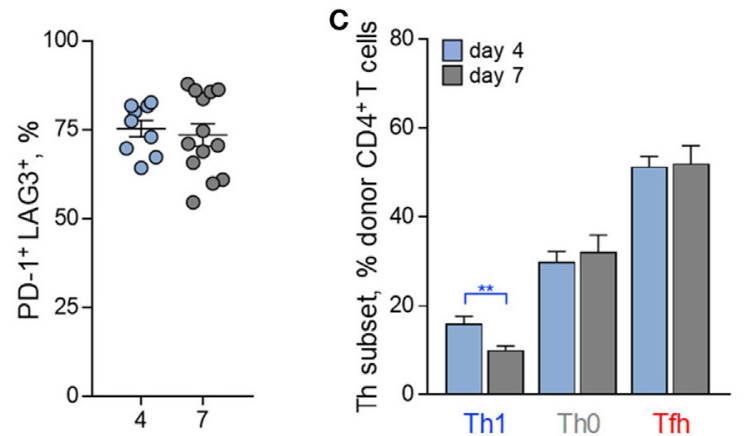

Days post infection
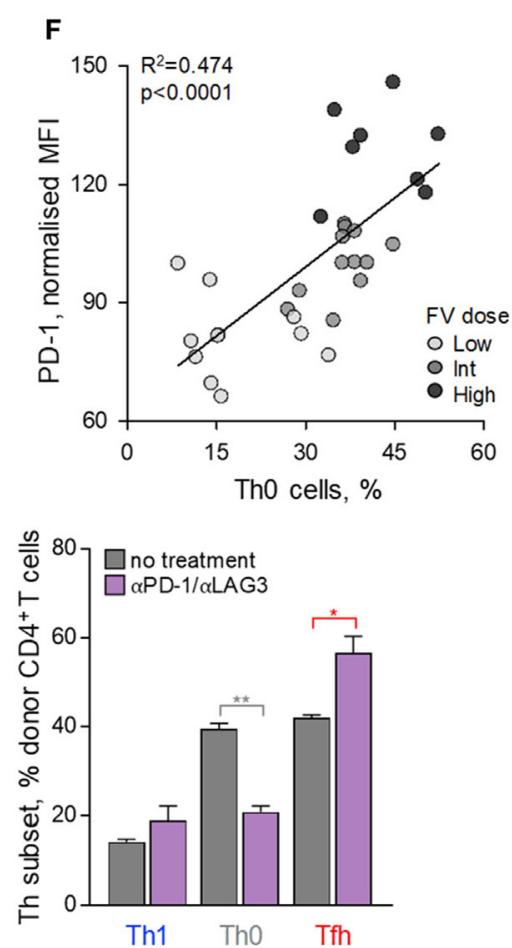

FIGURE 3 | Follicular helper (Tfh) cells maturation control by inhibitory receptor induction. CD4+ EF4.1 T cells were adoptively transferred into WT recipients infected with intermediate dose of Friend virus (FV) and analyzed by flow cytometry in the spleens on days $4(n=9)$ and 7 ( $n=13)$ post-transfer and infection. (A) Absolute number of env-reactive CD4+ T cells were recovered. (B) Flow cytometry profile (left) and mean frequency ( \pm SEM) (right) of PD- $1^{+}$LAG3 ${ }^{+}$cells within env-reactive donor CD4+ T cells. Each symbol is an individual mouse. (C) Mean frequency ( \pm SEM) of T helper (Th) subsets, defined by PSGL1 and CXCR5 expression, in env-reactive donor CD4 ${ }^{+}$T cells. (D) Representative flow cytometric profile of PD-1 and LAG3 expression (left), mean frequency ( \pm SEM) of PD-1+ LAG3+ cells, and (E) mean fluorescence intensity (MFI) of PD-1 staining in env-reactive CD4 ${ }^{+} \mathrm{T}$ cells isolated from the spleens of recipient mice on day 7 post transfer and infection with the indicated dose of FV. Each symbol is an individual mouse ( $n=11, n=14$, and $n=9$ for low, intermediate and high FV dose, respectively). (F) Correlation between the frequency of Th0 cells and the MFI of PD-1 expression in env-reactive donor CD4+ ${ }^{+}$cells from the same mice described in (D). (G) Flow cytometric analysis (left), absolute number (middle), and mean frequency ( \pm SEM) (right) of Th subsets, defined by PSGL1 and CXCR5 expression, in env-reactive donor CD4+ T cells, 7 days after transfer into FV-infected recipients with or without additional treatment with PD-1 and LAG3 blocking antibodies $(n=4$ from one of two representative experiments).

frequencies of env-reactive EF4.1 CD4 ${ }^{+} \mathrm{T}$ cells coexpressing PD-1 and LAG3, as well as the intensity of PD-1 expression, directly correlated with both FV loads and the proportion of the uncommitted Th0 subset of env-reactive EF4.1 CD4 ${ }^{+} \mathrm{T}$ cells (Figures 3D-F).

To test whether the early expression of PD-1 and LAG3 during FV infection was impeding Th differentiation of env-reactive EF4.1 $\mathrm{CD}^{+} \mathrm{T}$ cells, we treated recipient mice with PD-1 and
LAG3 blocking antibodies. Such treatment during FV infection was previously demonstrated to promote CTL differentiation of donor $\mathrm{CD}^{+} \mathrm{T}$ cells, which is not typically observed in $\mathrm{FV}$ infection (39). However, the CD4 ${ }^{+}$CTL subset induced by PD-1 and LAG3 blockade during FV infection constituted only 7\% of env-reactive EF4.1 CD4 ${ }^{+}$T cells (39), and it was possible that Tfh differentiation was still favoured. Indeed, PD-1 and LAG3 blockade during FV infection drove efficient differentiation of 
uncommitted Th0 env-reactive EF4.1 CD4 ${ }^{+} \mathrm{T}$ cells into Tfh cells, which again formed the large majority, with a small numerical increase in Th1 cells and a small numerical loss of Th0 cells (Figure 3G).

Together, these results suggested that FV infection induces primarily Tfh differentiation of env-reactive EF4.1 CD4 ${ }^{+} \mathrm{T}$ cells, partly restrained by inhibitory receptor expression, in turn induced by strong TCR signaling.

\section{Multifactorial Contribution to Tfh Cell Development During FV Infection}

The ability of FV infection to promote Tfh differentiation, especially under conditions when PD-1 and LAG3 were not maximally expressed or were blocked, seemed rather exceptional. A host of well-established intrinsic and extrinsic factors may help or hinder Tfh development and, alone or in combination, could account for the dominance of Tfh cells in the response to $\mathrm{FV}$ infection. Included among these factors are the avidity of the TCR, the form of antigen and duration of its presentation, the strength of interaction with B cells, and the cytokine environment, particularly the availability of IL-2.

We next investigated how modulation of one or more variables known to affect Tfh cell development, might shape differentiation of $\mathrm{CD}^{+} \mathrm{T}$ cells in response to FV. High TCR avidity has long been suggested as a contributor to Tfh cell differentiation in other systems and could contribute to Tfh bias also in response to FV infection (6-8). EF4.1 CD4 ${ }^{+}$T cells comprise a semi-polyclonal repertoire of env-reactive TCRs, differing in their avidity for the cognate antigen, according to the pairing of the transgenic TCR $\beta$ chain with endogenous TCR $\alpha$ chains $(30,41)$. Indeed, clonotypes with higher or lower TCR avidity for $\mathrm{H} 2-\mathrm{A}^{\mathrm{b}}-\mathrm{env}_{122-141}$ can be identified by the use of TCR $V \alpha 2$ or $V \alpha 3$ (non-V $\alpha 2$ ) endogenous chains, respectively, and used to examine the effect of TCR avidity on Th differentiation $(30,41)$. Nevertheless, Tfh development was broadly comparable between $\mathrm{V} \alpha 2^{+}$and $\mathrm{V} \alpha 3^{+}$env-reactive $\mathrm{CD} 4^{+} \mathrm{T}$ cell clonotypes, albeit development of Th1 cells appeared more efficient in lower avidity ${\mathrm{V} \alpha 3^{+}}^{+}$clonotypes in response to FV infection (Figure 4A). Thus, the bias in Tfh differentiation of EF4.1 CD4 ${ }^{+} \mathrm{T}$ cells was observed across clonotypes with a range of TCR avidities.

As an independent way to assess the effect of TCR avidity, we introduced mutations that alter the potency of the F-MLV env $_{122-141}$ epitope to stimulate particular clonotypes. Prior work highlighted the $\mathrm{L}$ residue at position 128 as an important contributor to recognition, particularly by higher avidity $\mathrm{V} \alpha 2^{+}$ env-reactive $\mathrm{CD}^{+} \mathrm{T}$ cell clonotypes (46). Epitopes carrying an L128I mutation behave as strong agonists for all clonotypes (46). F-MLVs expressing variants of the env ${ }_{122-141}$ epitope were also compared with N-tropic F-MLV (F-MLV-N), whose replication in $\mathrm{B} 6$ mice is restricted by the product of the $F v 1^{\mathrm{b}}$ allele, therefore reducing the amount of available antigen.

Friend murine leukemia virus carrying the $\operatorname{env}_{\mathrm{L} 128 \mathrm{I}}$ epitope induced significantly higher numbers of env-reactive EF4.1 $\mathrm{CD}^{+} \mathrm{T}$ cells than WT F-MLV-B, whereas F-MLV-N was less immunogenic (Figure 4B). Consistent with its potency,

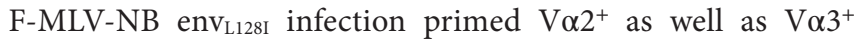

env-reactive $\mathrm{CD}^{+} \mathrm{T}$ cell clonotypes, in contrast to WT F-MLV infection, which favored $\mathrm{V} \alpha 2^{+}$clonotypes (Figure 4B). As a result, the frequency of $\mathrm{V} \alpha 2^{+}$clonotypes in env-reactive $\mathrm{CD} 4^{+}$ $\mathrm{T}$ cells was higher following infection with WT F-MLV than

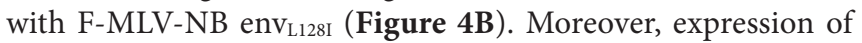
inhibitory receptors PD-1 and LAG3 was also regulated according to the potency of antigenic stimulation, reaching maximal

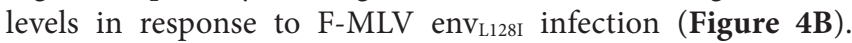
However, despite notable differences in induced clonal expansion and potency of antigenic stimulation between the mutant F-MLV viruses, differentiation of primed EF4.1 CD4 ${ }^{+} \mathrm{T}$ cells was highly comparable and still heavily skewed toward the Tfh subset (Figure 4C).

Th differentiation in response to a given antigen is also influenced by the context in which it is presented and in particular by its vector. We, therefore, compared the degree of Tfh differentiation of EF4.1 CD4 ${ }^{+} \mathrm{T}$ cells induced by F-MLV env ${ }_{122-141}$ in different immunization regimens. These included vaccination with Ad5. pIX-gp70 (47), transient env 124-138 $_{1}$ peptide immunization in Sigma adjuvant and transplantation of the FV-induced FBL-3 tumor cell line (38).

Each immunization regimen induced a characteristic pattern of clonotypic composition and inhibitory receptor expression (Figure 5A). In comparison with FV infection, Ad5.pIX-gp70 immunization induced a sizeable Tfh, as well as Th1 population of env-reactive $\mathrm{CD}^{+} \mathrm{T}$ cells, as previously shown for $\mathrm{CD}^{+}$ CTL development (39), without concomitant increases in the Th0 subset (Figures 5A,B). Peptide immunization induced lower numbers of env-reactive $\mathrm{CD} 4^{+} \mathrm{T}$ cells, but this reduction affected mostly Th0 and Tfh cells (Figures 5A,B). Finally, FBL-3 tumor cell immunization promoted expansion of Th1 cells, at the expense of Tfh cells, but also primed Th0 cells (Figures 5A,B). Thus, each immunization regimen elicited a somewhat distinct Th differentiation balance in env-reactive EF4.1 CD4 ${ }^{+} \mathrm{T}$ cells. Nevertheless, Tfh cells continued to be a prominent subset in response to all the regimens (Figure 5B).

Finally, the Tfh differentiation was examined in the context of altered lymphocyte interaction. To this end, EF4.1 CD4 ${ }^{+} \mathrm{T}$ cells were transferred into $\mathrm{FV}$-infected hosts deficient in B cells $\left(\mathrm{Ighm}^{-/-}\right)$, T cells $\left(\mathrm{Tcra}^{-/-}\right)$, or both $\mathrm{B}$ and $\mathrm{T}$ cells $\left(\mathrm{Rag}^{-/-}\right)$. Again, clonotypic composition or inhibitory receptor expression in the env-reactive donor $\mathrm{CD} 4^{+} \mathrm{T}$ cells was characteristic of each type of recipient (Figure 6A). Consistent with the established role for $\mathrm{B}$ cells in consolidating Tfh differentiation, env-reactive EF4.1 CD4 ${ }^{+} \mathrm{T}$ cells produced a larger fraction of Th1 cells in $\mathrm{Ighm}^{-1-}$ hosts, than in WT hosts (Figures 6A,B). Expectedly, enhanced Th1 differentiation in B cell-deficient hosts was at the expense of Tfh differentiation (Figures 6A,B). Despite this shift, however, Th1-phenotype env-reactive EF4.1 $\mathrm{CD}^{+} \mathrm{T}$ cells in $\mathrm{Ighm}^{-/-}$hosts did not outnumber those with a Tfh phenotype or those with an uncommitted Th0 phenotype, with all three subsets represented in almost equal proportions (Figure 6B). Surprisingly, in comparison with WT or $\mathrm{Ighm}^{-1-}$ hosts, Th1 differentiation of env-reactive EF4.1 CD4 ${ }^{+} \mathrm{T}$ cells was significantly more pronounced in $\mathrm{Tcra}^{-/-}$hosts, where Th1 cells now became the dominant subset (Figures 6A,B). Skewed differentiation was even more pronounced in Rag $2^{-1-}$ hosts, where 

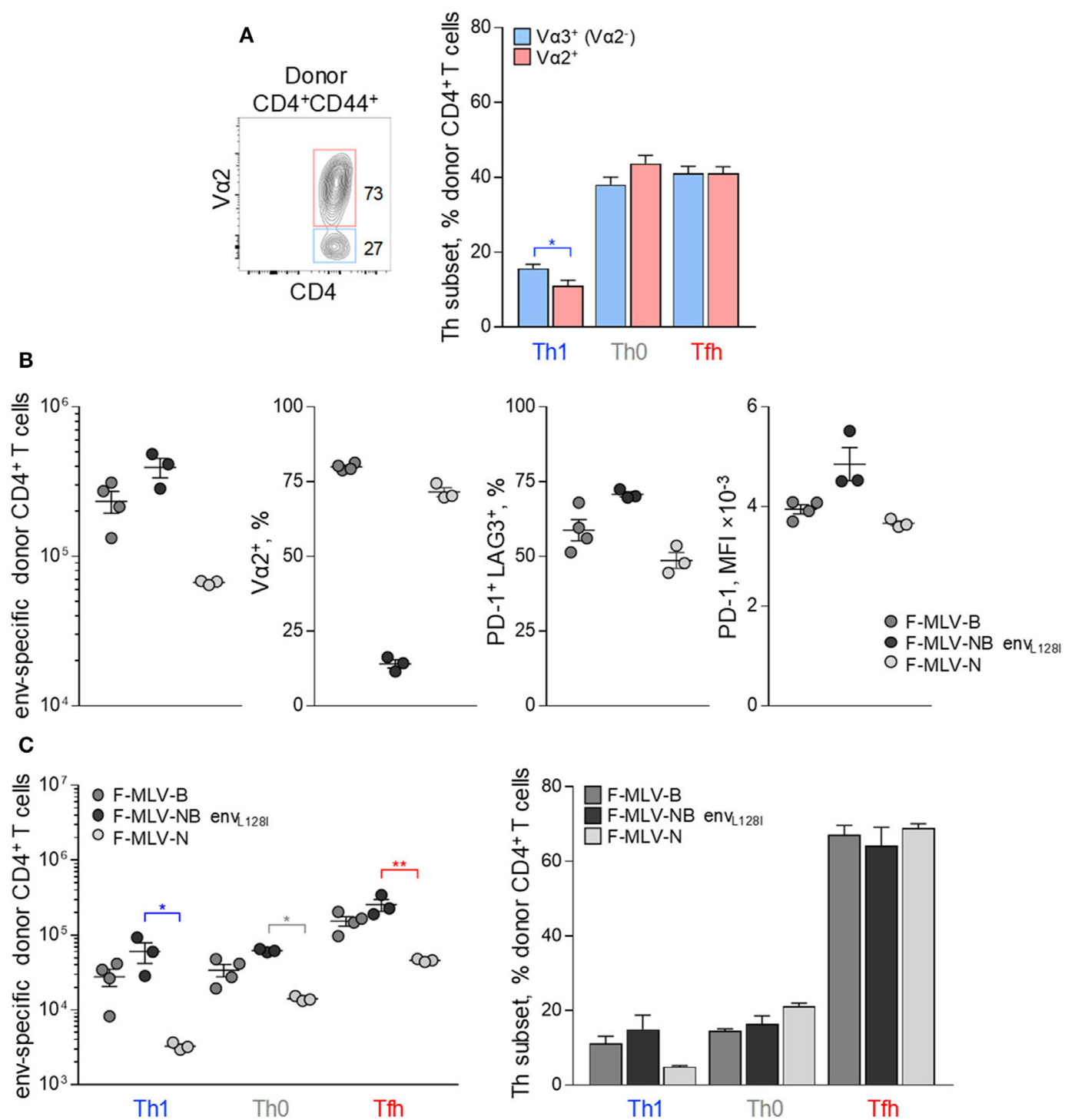

FIGURE 4 | Effect of TCR avidity on the follicular helper cells (Tfh) response to F-MLV env. (A) Flow cytometry example of V $\alpha 2$ expression (left) and mean frequency ( \pm SEM) (right) of T helper (Th) subsets, defined by PSGL1 and CXCR5 expression, in $V_{\alpha 2} 2^{+}$or $V_{\alpha} 3^{+}\left(V_{\alpha 2} 2^{-}\right)$env-reactive donor CD4 ${ }^{+} T$ cells, 7 days after transfer into Friend virus (FV) infected recipients $(n=10)$. (B) Characterization of clonal expansion and expression of V $\alpha 2$, PD-1, and LAG3 in env-reactive donor CD4+ T cells, 7 days post-transfer in WT recipient mice infected with $\sim 10^{4}$ infectious units of F-MLV-B, F-MLV-NB enVL1281, or F-MLV-N. (C) Absolute number (left) and mean frequency $\left( \pm\right.$ SEM) (right) of Th subsets, defined by PSGL1 and CXCR5 expression, in env-reactive donor CD4 ${ }^{+}$T cells from the same donor cells as in (B). One representative of two experiments with $n=4, n=3$, and $n=3$ mice for F-MLV-B, F-MLV-NB enVL128, and F-MLV-N infection, respectively, is shown.

env-reactive EF4.1 CD4 ${ }^{+} \mathrm{T}$ cells developed almost exclusively $(\sim 75 \%)$ into Th1 cells (Figures 6A,B). This shift in favor of Th1 differentiation in $\mathrm{Tcra}^{-/-}$and $\mathrm{Rag}^{-/-}$hosts was driven by approximately 60 -fold higher expansion of Th1 cells in such $\mathrm{T}$ cell-lymphopenic hosts, in comparison with $\mathrm{T}$ cell-replete hosts.

Together, these results highlighted the multitude of intrinsic and extrinsic factors that influence the balance of Tfh and Th1 differentiation in response to F-MLV env, but also indicated that each of these factors may contribute to a different degree, with $\mathrm{T}$ cell lymphopenia exerting the strongest influence.

\section{Reduced IL-2 Availability During FV Infection Facilitates Tfh Development}

In addition to increased availability of antigenic peptide-MHC complexes, a well-described effect of $\mathrm{T}$ cell lymphopenia is reduced $\mathrm{T}$ cell competition for other growth signals, such as cytokines. Consumption of effector $\mathrm{CD} 4^{+} \mathrm{T}$ cell-produced IL-2 by Treg cells or dendritic cells has been shown to promote Tfh differentiation, at the expense of Th1 differentiation in a variety of experimental systems (20, 24-26). It was, therefore, possible that the strong bias toward Tfh differentiation in FV infection was due to defective IL-2 signaling, either due to lack of production 
A

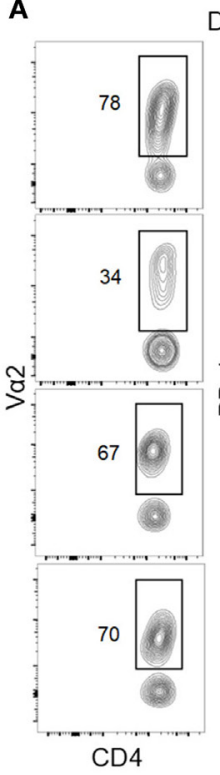

Donor CD4+CD44+

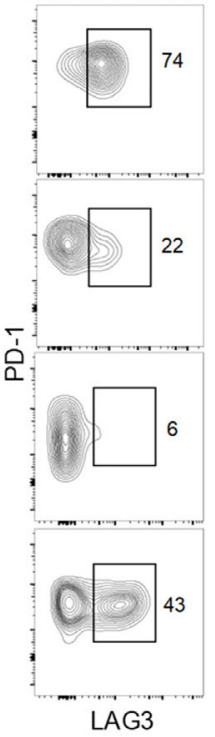

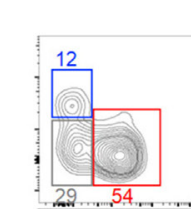

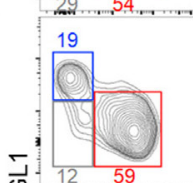

क.

(1) 25

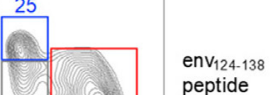

Antigen

FV
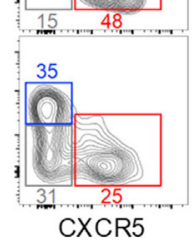

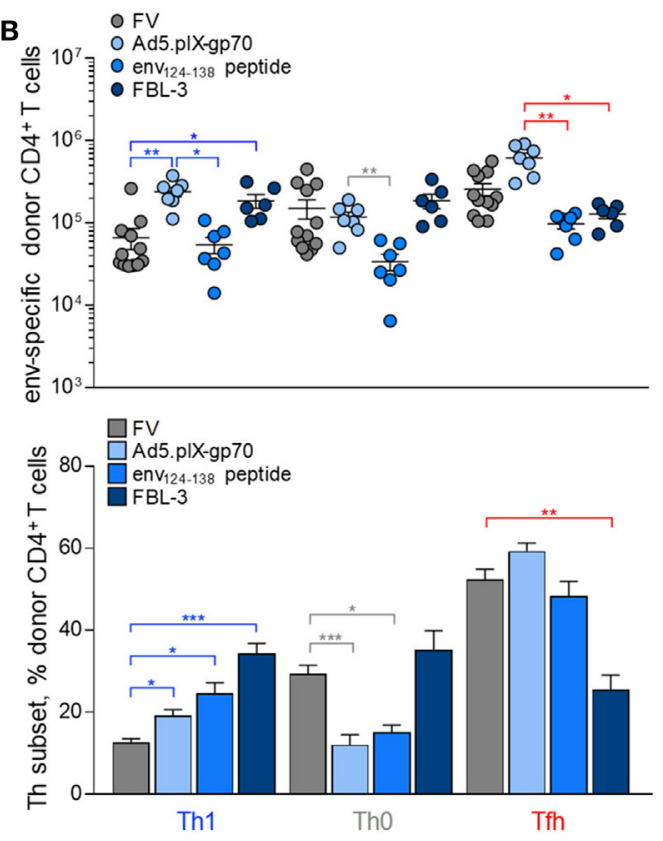

FIGURE 5 | Effect of immunization regimen on the follicular helper cells (Tfh) response to F-MLV env. (A) Flow cytometric analysis of $\bigvee_{\alpha} 2$, PD-1, LAG3, PSGL1, and CXCR5 expression in env-reactive CD4 ${ }^{+} T$ cells isolated from the spleens of WT recipients on day 7 post transfer and priming with the indicated immunization regimens [intermediate Friend virus (FV) infection, $n=3$; Ad5.pIX-gp70 vaccination, $n=7$; env ${ }_{124-138}$ peptide in Sigma Adjuvant System immunization, $n=7$; FBL-3 challenge, $n=6$ ]. (B) Absolute number (top) and mean frequency ( \pm SEM) (bottom) of Thelper (Th) subsets, defined by PSGL1 and CXCR5 expression, in env-reactive donor $\mathrm{CD} 4^{+} \mathrm{T}$ cells from the same donor cells as in (A).

A

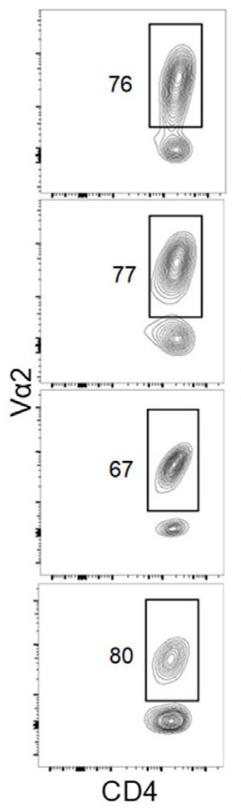

Donor $\mathrm{CD} 4^{+} \mathrm{CD} 44^{+}$

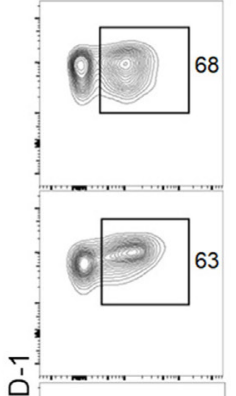

à.

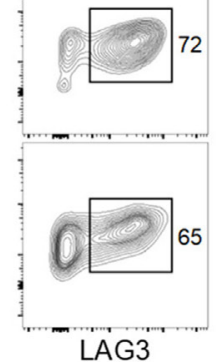

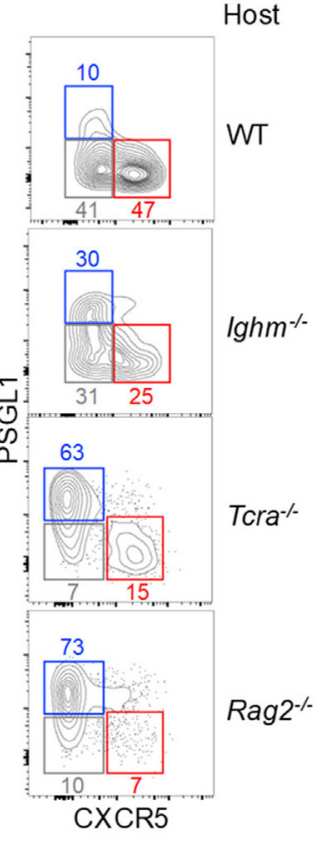

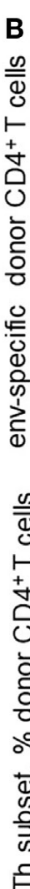

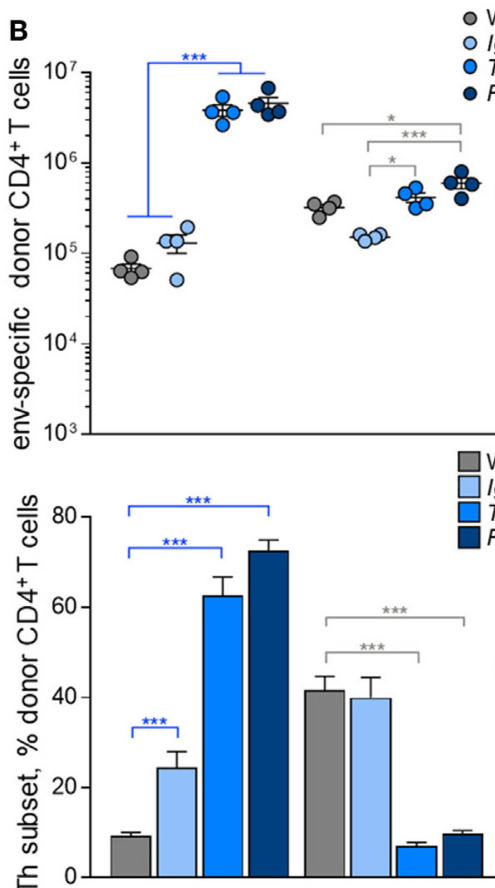

Th0

Th1
WT

$\mathrm{Ighm}^{-1-}$

Rag2-

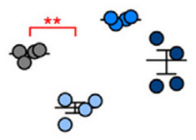

Tfh

FIGURE 6 | Effect of lymphocyte interaction on the follicular helper (Tfh) response to F-MLV env. (A) Flow cytometric analysis of Vo2, PD-1, LAG3, PSGL1, and CXCR5 expression in env-reactive CD4+ T cells isolated from the spleens of the indicated recipient mice on day 7 post transfer and intermediate Friend virus (FV) infection (WT host, $n=12$; lghm ${ }^{-/}$host, $n=6$; Tcra ${ }^{-/}$host, $n=6$; Rag2 $2^{-/}$host, $n=7$ ). (B) Absolute number (top) and mean frequency ( \pm SEM) (bottom) of T helper (Th) subsets, defined by PSGL1 and CXCR5 expression, in env-reactive donor CD4+ $\mathrm{T}$ cells from the same donor cells as in (A) 
or to increased consumption by cells other than effector $\mathrm{CD} 4^{+}$ T cells.

Consistent with this hypothesis, expression levels of CD25 were lower when env-specific EF4.1 CD4 ${ }^{+} \mathrm{T}$ cells were primed in WT

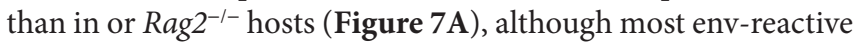
donor $\mathrm{CD}^{+} \mathrm{T}$ cells did not exhibit detectable CD25 expression in either type of host. As expression of CD25 may also be induced by IL-2 signaling, it was possible that, as well as reduced responsiveness of EF4.1 CD4 ${ }^{+} \mathrm{T}$ cells to IL-2, production or availability of IL-2 was reduced in WT hosts. Indeed, serum IL-2 was minimally detected during FV infection of lymphocyte-replete hosts, even when $\mathrm{B} 6$ mice with increased genetic susceptibility, provided by the $F v 2^{s}$ allele (36), were used (Figure 7B). In contrast, transfer of EF4.1 CD4 ${ }^{+} \mathrm{T}$ cells into $\mathrm{FV}$-infected lymphocyte-deficient Rag1 $^{-/-}$hosts led to readily detectable serum IL-2 (Figure 7C).

IL-2 transcription was previously found to be reduced in envspecific EF4.1 CD4 ${ }^{+} \mathrm{T}$ cells responding to $\mathrm{FV}$ infection than to Ad5.pIX-gp70 immunization (37). However, relative reduction of IL-2 transcription in FV infection could simply reflect the strong skewing toward Tfh cells, which may not produce IL-2. To further investigate the nature of IL-2-producing $\mathrm{CD} 4^{+} \mathrm{T}$ cells, we searched for correlates of IL-2 production in single-cell RNAsequencing data obtained with env-specific EF4.1 CD4 ${ }^{+} \mathrm{T}$ cells primed by FV or Ad5.pIX-gp70 (39). This analysis revealed that most EF4.1 CD4 ${ }^{+} \mathrm{T}$ cells transcribing Il2 in response to FV infection, also transcribed $I l 21, I l 10$ or Ifng (Figure 7D). In contrast, transcription of distinct cytokine genes was largely restricted to different EF4.1 CD4 ${ }^{+} \mathrm{T}$ cells responding to Ad5.pIX-gp70 immunization, with most Il2-positive cells lacking transcripts for other cytokines, with the exception of Gzmb (Figure 7D). These data suggest that env-specific EF4.1 $\mathrm{CD}^{+}{ }^{+} \mathrm{T}$ cells producing IL-2 following FV infection or Ad5.pIX-gp70 immunization display disparate functional properties. Together, these results highlighted the important contribution of reduced IL-2 production and availability to the dominant Tfh skewing in the $\mathrm{CD} 4^{+} \mathrm{T}$ cell response to $\mathrm{FV}$ infection.
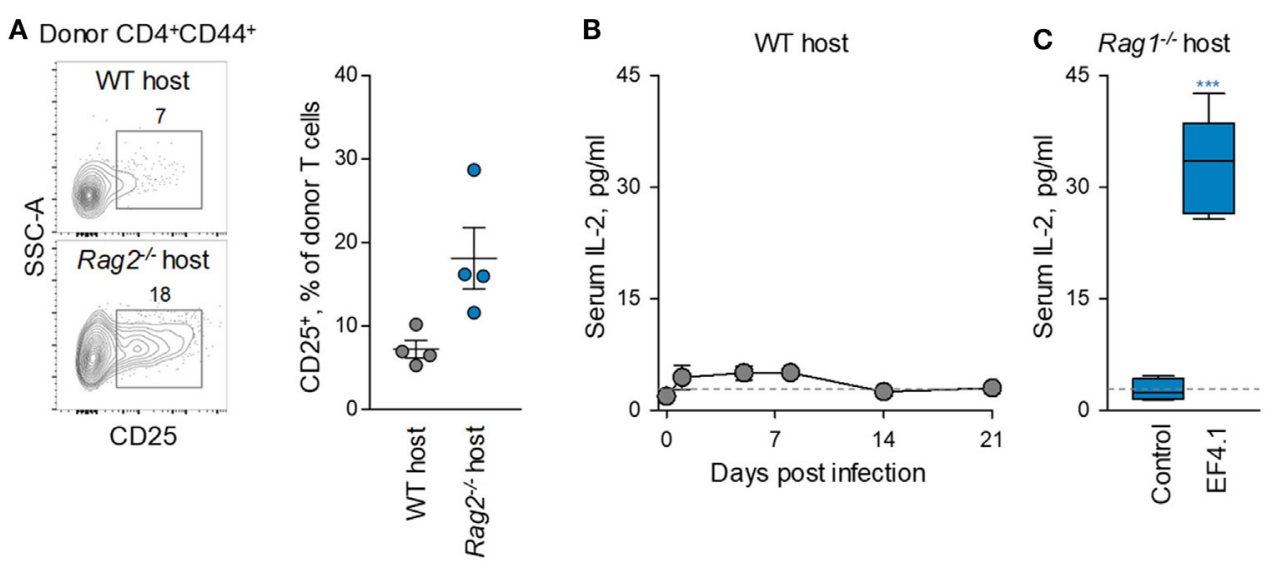

D
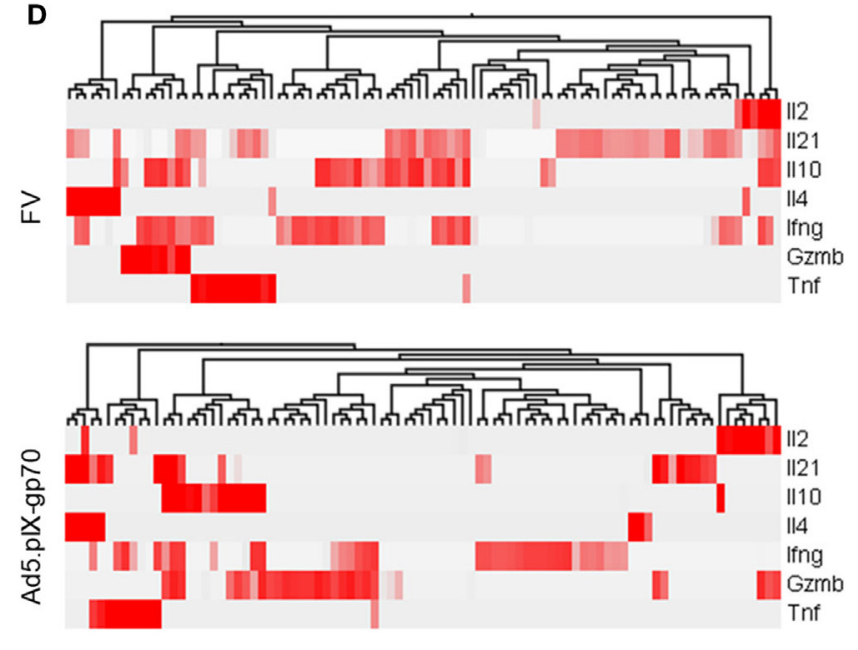

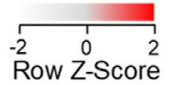

Row Z-Score

FIGURE 7 | Defective IL-2-IL-2R axis in CD4+ T cell response to F-MLV env. (A) Flow cytometric example (left) and frequency of CD25 expressing cells (right) expression in env-reactive donor CD4+ $\mathrm{T}$ cells, 7 days after transfer into Friend virus (FV) infected WT or Rag2 ${ }^{-/-}$recipients. (B) Mean ( \pm SEM) levels of IL-2 in the serum of WT B6.FV2 ${ }^{s}$ mice at different time-points after intermediate FV infection ( $n=4-5$ per time-point). (C) Mean ( \pm SEM) levels of IL-2 in the serum of Rag $1^{-/-}$ mice 35 days after infection with an intermediate dose of FV (control, $n=4)$ and those additionally received CD4+ EF4.1 T cells at the time of infection (EF4.1, $n=5$ ). (D) Heatmap and hierarchical clustering of cytokine gene expression, assessed by single-cell RNA sequencing, in env-reactive donor CD4+ $T$ cells isolated from the spleens of WT recipients infected with FV or immunized with Ad5.plX-gp70. Each column represents an individual cell. 


\section{Distinct Correlates of Tfh and Th1 Differentiation in Response to FV Infection}

To investigate possible correlates of Tfh bias in FV infection, we compared a number of variables relating to the strength of
TCR signaling. This was assessed independently by the degree of clonal expansion and resulting clonotypic composition, the degree of surface TCR downregulation, the activity of a Nur77GFP reporter (Figure 8A) (31), and the degree of PD-1 and
A

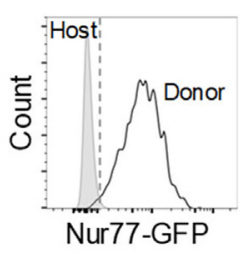

\section{B}

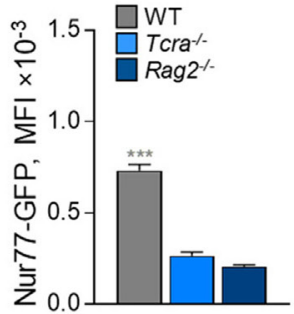

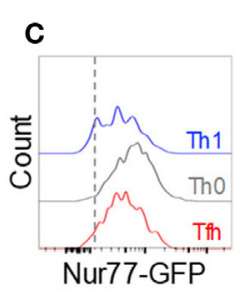

E

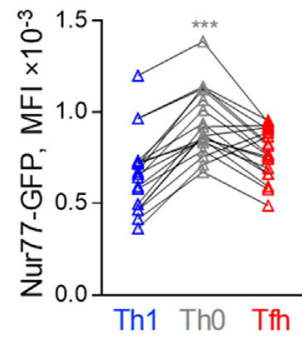

。
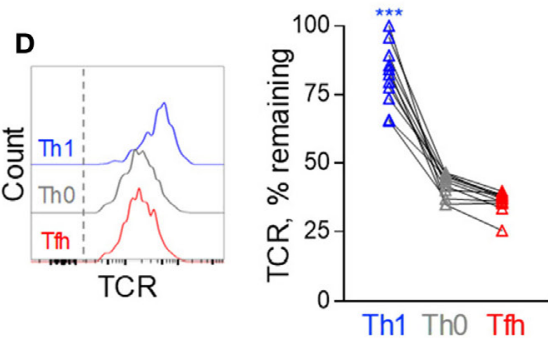

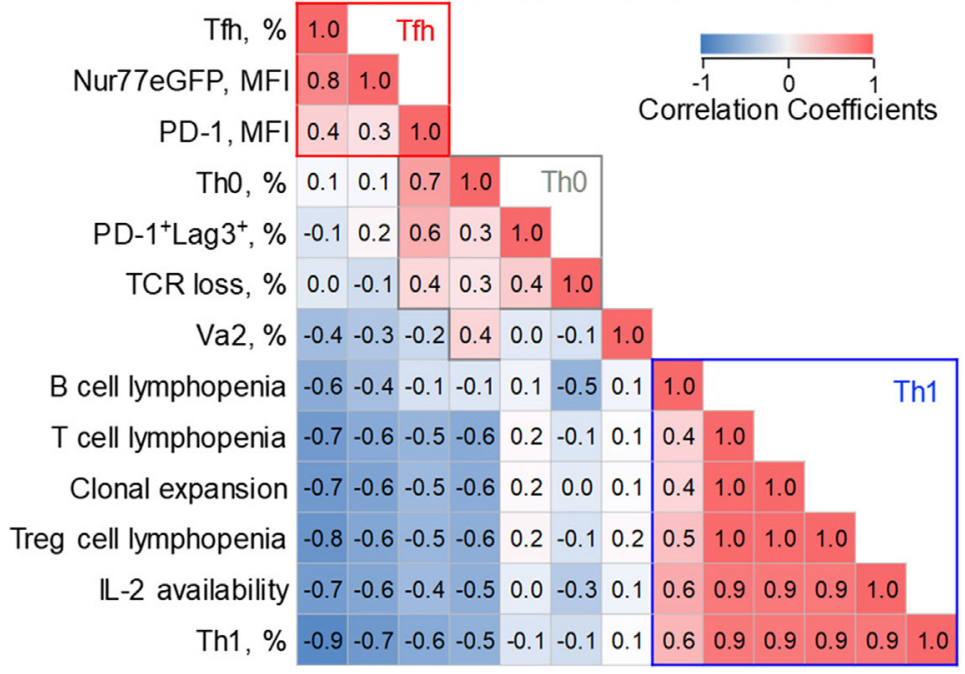

FIGURE 8 | Correlates of follicular helper cells (Tfh) and Th1 CD4+ $T$ cell response to F-MLV env. (A) Representative flow cytometric profile of GFP expression in Nur77-GFP EF4.1 doubly transgenic env-reactive donor CD4+ $T$ cells, 7 days post transfer into Friend virus (FV)-infected WT recipients. (B) Mean fluorescence intensity (MFI) $( \pm$ SEM) of Nur77-GFP expression (left) and levels of TCR $\beta$ expression (right) in env-reactive donor CD4+ $T$ cells, 7 days post transfer into WT ( $n=4)$, Tcra $^{-/-}(n=3)$ or Rag2 $2^{-/-}(n=4)$ recipients, infected with an intermediate dose of FV. One representative of three experiments is shown. (C) Flow cytometric profile (left) and MFI of Nur77-GFP expression (right) and (D) flow cytometric profile (left) and levels of TCR $\beta$ expression (right) in T helper (Th) subsets, defined by PSGL1 and CXCR5 expression, in env-reactive donor CD4 ${ }^{+}$T cells, 7 days after transfer into FV-infected WT recipients $(n=19)$. Lines connect values from individual recipients. (E) Matrix of correlation coefficients between the indicated variables and Th subset differentiation. 
LAG3 expression. Although all these parameters can be directly affected by the strength of TCR signaling, their precise relationship or indeed their effect on Tfh differentiation is not necessarily linear.

For example, EF4.1 $\mathrm{CD}^{+}{ }^{+} \mathrm{T}$ cells primed in WT hosts exhibited the strongest Nur77-GFP signals and highest degree

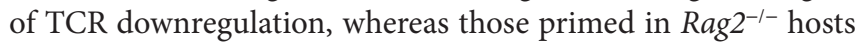
displayed the opposite phenotype (Figure 8B), indicating a direct correlation between Nur77-GFP intensity and TCR downregulation. However, EF4.1 CD4 ${ }^{+} \mathrm{T}$ cells primed in $\mathrm{Tcra}^{-/-}$hosts downregulated their TCRs to the same degree as in WT hosts, but without the accompanying increase in Nur77-GFP reporter activity (Figure 8B). Also, partly discordant were the degree of TCR downregulation and Nur77-GFP reporter activity in Th functional subsets primed in the same host (Figures 8C,D). Th1 EF4.1 CD4 ${ }^{+} \mathrm{T}$ cells retained significant amounts of surface TCR, compared with Tfh or Th0 cells primed in WT hosts (Figures 8C,D), likely due to infrequent interaction of the former subset with B cells. However, Th0 cells exhibited significantly higher Nur77-GFP reporter activity, than either Th1 or Tfh cells in these hosts, despite comparable TCR downregulation with Thh cells (Figures 7C,D). These results suggested that, although modulation of TCR signal strength is evidently different in EF4.1 $\mathrm{CD}^{+} \mathrm{T}$ cells primed in T cell-replete or $\mathrm{T}$ cell-deficient hosts, the effect of T cell lymphopenia on Th differentiation operated through additional mechanisms.

Given the complex patterns of correlation between independently measured variables and the degree of Th and Th1 differentiation, we next calculated a correlation matrix (Figure 8E). To this end, we assessed the relative contribution and possible interaction of 13 variables controlling Tfh differentiation measured in the 11 separate combinations of host and immunization or infection regimen described here. This analysis indicated three distinguishable clusters across all conditions, corresponding to each of the three major Th subsets observed in FV infection. Development of Th cells correlated most strongly with the activity of the Nur77-GFP reporter, taken to indicate the strength of signaling EF4.1 $\mathrm{CD}^{+} \mathrm{T}$ cells received, and also with the intensity of PD-1 expression (Figure 8E). In contrast, Th1 development exhibited strong anti-correlation with Nur77-GFP reporter activity and PD-1 expression levels and instead correlated with $\mathrm{T}$ cell lymphopenia and the availability of IL-2, together likely driving T cell clonal expansion (Figure 8E). Finally, uncommitted Th0 cells, although sharing many attributes with Tfh cells, appear to cluster separately, correlating strongly with LAG-3 expression, the degree of TCR downregulation and, the use of high-affinity TCRs (Figure 8E). Thus, our data suggest that Tfh differentiation is promoted by an optimal degree of TCR signaling, as well as by $\mathrm{T}$ cell competition.

\section{DISCUSSION}

It is now well recognized that both $\mathrm{T}$ cell-intrinsic and $\mathrm{T}$ cellextrinsic factors shape the balance of $\mathrm{CD} 4^{+} \mathrm{T}$ cell differentiation into distinguishable functional subsets $(1-8)$. However, the relative contribution of each of these factors in isolation or their potential intersection with each other in the context of diverse immunological challenges is still not fully understood. Here, we provided evidence to suggest that the $\mathrm{CD} 4^{+} \mathrm{T}$ cell response to a model retroviral antigen, presented during natural infection, is heavily skewed toward Tfh differentiation. This allowed us to identify the variables that best correlate with the degree of Tfh differentiation in this model and to accurately quantify their contribution.

The variable that exhibited the closest positive correlation with Tfh differentiation of env-reactive $\mathrm{CD} 4^{+} \mathrm{T}$ cells in all the conditions studied was the strength of TCR signaling, translating to increased transcription of the Nur77-GFP reporter. Also, directly correlating with both the degree of Tfh differentiation and Nur77-GFP reporter activity was the intensity of PD-1 expression. These findings are consistent with an instructive model, whereby stronger TCR signaling in Th cell precursors favors Tfh development, likely through stronger induction of the Tfh-promoting cytokine IL-21 $(42,48,49)$.

Although stronger TCR signaling in Tfh cells was indicated by the increase in Nur77-GFP reporter activity and the intensity of PD-1 expression, it should be noted that not all correlates of TCR signaling followed a similar pattern. For example, the degree of surface TCR downregulation, generally proportional to TCR signal strength (50), did not correlate with the degree of Tfh differentiation. Moreover, expression of LAG3, which is also transiently induced by strong TCR signals $(51,52)$, showed no positive correlation with Tfh differentiation. Instead, the envreactive $\mathrm{CD} 4^{+} \mathrm{T}$ cells with the highest TCR signal, assessed by both the activity of the Nur77-GFP reporter and the degree of surface TCR downregulation, appeared inhibited in their commitment to either the Th1 or Tfh subsets. These cells, which we refer to as uncommitted Th0 cells (44), also strongly correlated with co-expression of the inhibitory receptors PD-1 and LAG3.

Seemingly uncommitted Th 0 cells are not typically observed in acute viral infections (44), but a similar population lacking either Th1 or Tfh characteristics has been described in $\mathrm{CD}^{+} \mathrm{T}$ cells primed during the chronic phase of LCMV Cl13 infection (18). In that model, the emergence of Th0 cells was linked to an initial defect in effector differentiation, indirectly caused by chronic IFN type I production (18). Eventually, $\mathrm{CD}^{+} \mathrm{T}$ cells primed during chronic LCMV-specific developed almost exclusively into Tfh cells (18).

The env-reactive $\mathrm{CD}^{+} \mathrm{T}$ cells with $\mathrm{Th} 0$ characteristics observed during FV infection are also closely related to Tfh cells, highlighting parallels between acute FV infection and chronic LCMV infection. However, as IFN type I production is not a prominent feature of acute FV infection (40), defective effector differentiation must have alternative explanations. Our results with the FV model suggest that TCR signaling above an optimal strength restrains differentiation of env-reactive $\mathrm{CD} 4^{+} \mathrm{T}$ cells, which would otherwise be committed to the Tfh subset. Indeed, in addition to displaying the highest Nur77-GFP reporter activity and preferentially expressed genes involved in active metabolism, Th0 cells were most noticeable in conditions associated with the highest antigenic load or potency. Furthermore, the frequency of $\mathrm{Th} 0$ in env-reactive $\mathrm{CD} 4^{+} \mathrm{T}$ cells was positively correlated with the percentage of PD-1 and LAG3 coexpressing cells across the various conditions studied and was reduced by anti-PD- 1 and 
anti-LAG3 treatment during FV infection, which promoted their differentiation into Tfh cells. Notably, Tfh differentiation was also reported to be enhanced by anti-PD-1 and anti-LAG3 treatment during Plasmodium yoelii infection of mice (53), indicating that this pathway is restricting Tfh differentiation in persistent parasitic, as well as viral infection. Thus, our results suggest that Tfh differentiation is most efficiently induced by an optimal range of TCR signal strength.

Although evidently influenced by TCR signal strength, Tfh differentiation of the $\mathrm{CD}^{+} \mathrm{T}$ cell response to F-MLV env was independent of TCR clonotypic affinity, as previously suggested (37, 41, 42). Env-reactive $\mathrm{CD}^{+}{ }^{+} \mathrm{T}$ cells bearing identical highaffinity clonotypic TCRs (identified by the use of endogenous V $\alpha 2$ chains) were found both in the Tfh and Th1 subsets at comparable frequencies. Notably, despite comparable clonotypic TCR usage and Nur77-GFP reporter activity, Th1 env-reactive CD4 ${ }^{+} \mathrm{T}$ cells retained nearly the full amount of surface TCR, when compared with their Tfh counterparts in the same host, which had nearly lost their surface TCR expression. Therefore, the differential strength of TCR signals received by Th1 and Tfh cells cannot be solely attributed to differences in clonotypic TCR affinity. Instead, at least part of the differential TCR signaling between Th1 and Tfh cells is secondary to their differentiation and likely the result of their anatomic localization and interaction with distinct APC types. Supporting this notion, downregulation of surface TCR expression in $\mathrm{CD}^{+} \mathrm{T}$ cells has been previously shown, in FV infection (42), as well as in other model systems $(54,55)$, to be dependent on interaction with antigen-presenting B cells. Retention of surface TCR preferentially in Th1 cells would, therefore, suggest reduced B cell interaction. A central role for the APC type in determining or consolidating Th1 or Tfh effector differentiation may also underlie the propensity of different vaccine vectors or immunization regimens to induce distinct ratios of Th1 and Tfh response to a given antigen.

In addition to interaction with distinct APC types, our findings also support the concept that interaction and/or competition between $\mathrm{T}$ cells are also critical in determining effector differentiation, particularly, of Th1 cells. Although expectedly B cell deficiency did promote Th1 responses at the expense of Tfh responses, the strongest positive effect on Th1 differentiation was $\mathrm{T}$ cell lymphopenia. Indeed, the proportion of Th1 cells was approximately threefold higher in T cell deficiency than in $\mathrm{B}$ cell deficiency. Conditions conducive for Th1 differentiation in $\mathrm{T}$ cell lymphopenia are likely to involve deficiency in Treg cells, which can reduce availability of IL-2, thus promoting Tfh differentiation (24). However, an additional role for primary IL-2 production by effector $\mathrm{CD} 4^{+} \mathrm{T}$ cells was also indicated by

\section{REFERENCES}

1. O'shea JJ, Paul WE. Mechanisms underlying lineage commitment and plasticity of helper CD4+ T cells. Science (2010) 327(5969):1098-102. doi:10.1126/ science.1178334

2. Zhu J, Yamane H, Paul WE. Differentiation of effector CD4 T cell populations. Annu RevImmunol (2010) 28:445-89. doi:10.1146/annurev-immunol-030409101212

3. Crotty S. T follicular helper cell differentiation, function, and roles in disease. Immunity (2014) 41(4):529-42. doi:10.1016/j.immuni.2014.10.004 single-cell RNA-sequencing analysis. Although Th1-promoting Il2 transcription was still detected in single $\mathrm{CD} 4^{+} \mathrm{T}$ cells despite the heavy skewing toward a Tfh response following FV infection, this was always accompanied by transcription of Th1-suppressing cytokines, such as Il21 and Il10. In contrast, Il2 transcription in single $\mathrm{CD}^{+} \mathrm{T}$ cells primed by Ad5.pIX-gp70 vaccination partly overlapped only with $G z m b$ transcription.

Together, our results highlight the potent contribution of T cell-extrinsic variables to determine the relative balance of Th1 and Tfh responses. Manipulating these variables in vaccination regimens in order to achieve a balance of $\mathrm{CD} 4^{+} \mathrm{T}$ cell effector differentiation appropriate for the respective context (e.g., viral infection or cancer) will be the next important challenge.

\section{ETHICS STATEMENT}

All animal experiments were approved by the ethical committee of the Francis Crick Institute, and conducted according to local guidelines and UK Home Office regulations under the Animals Scientific Procedures Act 1986 (ASPA).

\section{AUTHOR CONTRIBUTIONS}

LD and TD performed the experiments and analyzed the data. LD and GK wrote the manuscript. GK supervised the study and contributed to data analysis.

\section{ACKNOWLEDGMENTS}

We wish to thank Dr. Kristin A. Hogquist for the Nur77-GFP mice, Dr. Kim Hasenkrug for FV and FBL-3 stocks, and Dr. Ulf Dittmer for the Ad5.pIX-gp70 stocks. We are grateful for assistance from the Flow Cytometry and Biological Resource Facilities at the Francis Crick Institute.

\section{FUNDING}

This work was supported by the Francis Crick Institute, which receives its core funding from Cancer Research UK (FC001099), the UK Medical Research Council (FC001099), and the Wellcome Trust (FC001099).

\section{SUPPLEMENTARY MATERIAL}

The Supplementary Material for this article can be found online at https://www.frontiersin.org/articles/10.3389/fimmu.2018.01260/ full\#supplementary-material.

4. Vinuesa CG, Linterman MA, Yu D, Maclennan IC. Follicular helper T Cells. Annu Rev Immunol (2016) 34:335-68. doi:10.1146/annurev-immunol-041015-055605

5. Qi H. T follicular helper cells in space-time. Nat Rev Immunol (2016) 16(10):612-25. doi:10.1038/nri.2016.94

6. Linterman MA, Vinuesa CG. Signals that influence T follicular helper cell differentiation and function. Semin Immunopathol (2010) 32(2):183-96. doi:10.1007/s00281-009-0194-Z

7. Lo WL, Allen PM. Self-awareness: how self-peptide/MHC complexes are essential in the development of T cells. Mol Immunol (2013) 55(2):186-9. doi:10.1016/j.molimm.2012.10.028 
8. Thorborn G, Young GR, Kassiotis G. Effective T helper cell responses against retroviruses: are all clonotypes equal? JLeukoc Biol (2014) 96(1):27-37. doi:10.1189/jlb.2RI0613-347R

9. Choi YS, Gullicksrud JA, Xing S, Zeng Z, Shan Q, Li F, et al. LEF-1 and TCF-1 orchestrate $\mathrm{T}(\mathrm{FH})$ differentiation by regulating differentiation circuits upstream of the transcriptional repressor Bcl6. Nat Immunol (2015) 16(9):980-90. doi:10.1038/ni.3226

10. Gullicksrud JA, Li F, Xing S, Zeng Z, Peng W, Badovinac VP, et al. Differential requirements for Tcf1 long isoforms in CD8(+) and CD4(+) T cell responses to acute viral infection. J Immunol (2017) 199(3):911-9. doi:10.4049/ jimmunol.1700595

11. Lee J, Hashimoto M, Im SJ, Araki K, Jin HT, Davis CW, et al. Adenovirus serotype 5 vaccination results in suboptimal CD4 T helper 1 responses in mice. J Virol (2017) 91(5):e1132-1116. doi:10.1128/jvi.01132-16

12. Shaw LA, Belanger S, Omilusik KD, Cho S, Scott-Browne JP, Nance JP, et al. Id 2 reinforces TH1 differentiation and inhibits E2A to repress TFH differentiation. Nat Immunol (2016) 17(7):834-43. doi:10.1038/ni.3461

13. Wu T, Shin HM, Moseman EA, Ji Y, Huang B, Harly C, et al. TCF1 is required for the $\mathrm{T}$ follicular helper cell response to viral infection. Cell Rep (2015) 12(12):2099-110. doi:10.1016/j.celrep.2015.08.049

14. Xu L, Cao Y, Xie Z, Huang Q, Bai Q, Yang X, et al. The transcription factor TCF-1 initiates the differentiation of $\mathrm{T}(\mathrm{FH})$ cells during acute viral infection. Nat Immunol (2015) 16(9):991-9. doi:10.1038/ni.3229

15. Boettler T, Choi YS, Salek-Ardakani S, Cheng Y, Moeckel F, Croft M, et al. Exogenous OX40 stimulation during lymphocytic choriomeningitis virus infection impairs follicular Th cell differentiation and diverts CD4 T cells into the effector lineage by upregulating Blimp-1. J Immunol (2013) 191(10):5026-35. doi:10.4049/jimmunol.1300013

16. Lewis GM, Wehrens EJ, Labarta-Bajo L, Streeck H, Zuniga EI. TGF-beta receptor maintains CD4 T helper cell identity during chronic viral infections. J Clin Invest (2016) 126(10):3799-813. doi:10.1172/jci87041

17. Maine CJ, Teijaro JR, Marquardt K, Sherman LA. PTPN22 contributes to exhaustion of T lymphocytes during chronic viral infection. Proc Natl Acad Sci U S A (2016) 113(46):E7231-9. doi:10.1073/pnas.1603738113

18. Osokine I, Snell LM, Cunningham CR, Yamada DH, Wilson EB, Elsaesser HJ, et al. Type I interferon suppresses de novo virus-specific CD4 Th1 immunity during an established persistent viral infection. Proc Natl Acad Sci U S A (2014) 111(20):7409-14. doi:10.1073/pnas.1401662111

19. Snell LM, Osokine I, Yamada DH, De La Fuente JR, Elsaesser HJ, Brooks DG. Overcoming CD4 Th1 cell fate restrictions to sustain antiviral CD8 T cells and control persistent virus infection. Cell Rep (2016) 16(12):3286-96. doi:10.1016/j.celrep.2016.08.065

20. Ballesteros-Tato A, Leon B, Graf BA, Moquin A, Adams PS, Lund FE, et al. Interleukin-2 inhibits germinal center formation by limiting $\mathrm{T}$ follicular helper cell differentiation. Immunity (2012) 36(5):847-56. doi:10.1016/j. immuni.2012.02.012

21. Leon B, Bradley JE, Lund FE, Randall TD, Ballesteros-Tato A. FoxP3+ regulatory T cells promote influenza-specific Tfh responses by controlling IL-2 availability. Nat Commun (2014) 5:3495. doi:10.1038/ncomms4495

22. Mcdonald PW, Read KA, Baker CE, Anderson AE, Powell MD, BallesterosTato A, et al. IL-7 signalling represses Bcl-6 and the TFH gene program. Nat Commun (2016) 7:10285. doi:10.1038/ncomms10285

23. Read KA, Powell MD, Baker CE, Sreekumar BK, Ringel-Scaia VM, Bachus H, et al. Integrated STAT3 and Ikaros zinc finger transcription factor activities regulate Bcl-6 expression in CD4(+) Th cells. J Immunol (2017) 199(7): 2377-87. doi:10.4049/jimmunol.1700106

24. Botta D, Fuller MJ, Marquez-Lago TT, Bachus H, Bradley JE, Weinmann AS, et al. Dynamic regulation of $\mathrm{T}$ follicular regulatory cell responses by interleukin 2 during influenza infection. Nat Immunol (2017) 18(11):1249-60. doi:10.1038/ni.3837

25. Li J, Lu E, Yi T, Cyster JG. EBI2 augments Tfh cell fate by promoting interaction with IL-2-quenching dendritic cells. Nature (2016) 533(7601):110-4. doi:10.1038/nature17947

26. Ray JP, Staron MM, Shyer JA, Ho PC, Marshall HD, Gray SM, et al. The interleukin-2-mTORc1 kinase axis defines the signaling, differentiation, and metabolism of T helper 1 and follicular B helper T cells. Immunity (2015) 43(4):690-702. doi:10.1016/j.immuni.2015.08.017

27. Weinstein JS, Bertino SA, Hernandez SG, Poholek AC, Teplitzky TB, Nowyhed HN, et al. B cells in T follicular helper cell development and function: separable roles in delivery of ICOS ligand and antigen. J Immunol (2014) 192(7):3166-79. doi:10.4049/jimmunol.1302617

28. Hasenkrug KJ, Chesebro B. Immunity to retroviral infection: the friend virus model. Proc Natl Acad Sci U S A (1997) 94(15):7811-6. doi:10.1073/ pnas.94.15.7811

29. Tsuji-Kawahara S, Kawabata H, Matsukuma H, Kinoshita S, Chikaishi T, Sakamoto M, et al. Differential requirements of cellular and humoral immune responses for Fv2-associated resistance to erythroleukemia and for regulation of retrovirus-induced myeloid leukemia development. J Virol (2013) 87(24):13760-74. doi:10.1128/JVI.02506-13

30. Antunes I, Tolaini M, Kissenpfennig A, Iwashiro M, Kuribayashi K, Malissen B, et al. Retrovirus-specificity of regulatory $\mathrm{T}$ cells is neither present nor required in preventing retrovirus-induced bone marrow immune pathology. Immunity (2008) 29(5):782-94. doi:10.1016/j.immuni.2008.09.016

31. Moran AE, Holzapfel KL, Xing Y, Cunningham NR, Maltzman JS, Punt J, et al. T cell receptor signal strength in Treg and iNKT cell development demonstrated by a novel fluorescent reporter mouse. JExp Med (2011) 208(6):1279-89. doi:10.1084/jem.20110308

32. Kitamura D, Roes J, Kuhn R, Rajewsky K. A B cell-deficient mouse by targeted disruption of the membrane exon of the immunoglobulin $\mathrm{mu}$ chain gene. Nature (1991) 350(6317):423-6. doi:10.1038/350423a0

33. Philpott KL, Viney JL, Kay G, Rastan S, Gardiner EM, Chae S, et al. Lymphoid development in mice congenitally lacking $\mathrm{T}$ cell receptor alpha betaexpressing cells. Science (1992) 256(5062):1448-52. doi:10.1126/science.1604321

34. Mombaerts P, Iacomini J, Johnson RS, Herrup K, Tonegawa S, Papaioannou VE. RAG-1-deficient mice have no mature B and T lymphocytes. Cell (1992) 68(5):869-77. doi:10.1016/0092-8674(92)90030-G

35. Monroe RJ, Seidl KJ, Gaertner F, Han S, Chen F, Sekiguchi J, et al. RAG2:GFP knockin mice reveal novel aspects of RAG2 expression in primary and peripheral lymphoid tissues. Immunity (1999) 11(2):201-12. doi:10.1016/ S1074-7613(00)80095-3

36. Marques R, Antunes I, Eksmond U, Stoye J, Hasenkrug K, Kassiotis G. B lymphocyte activation by coinfection prevents immune control of friend virus infection. JImmunol (2008) 181(5):3432-40. doi:10.4049/ jimmunol.181.5.3432

37. Thorborn G, Ploquin MJ, Eksmond U, Pike R, Bayer W, Dittmer U, et al. Clonotypic composition of the CD4+ $\mathrm{T}$ cell response to a vectored retroviral antigen is determined by its speed. J Immunol (2014) 193(4):1567-77. doi:10.4049/jimmunol.1400667

38. Klarnet JP, Kern DE, Okuno K, Holt C, Lilly F, Greenberg PD. FBL-reactive CD8+ cytotoxic and CD4+ helper T lymphocytes recognize distinct friend murine leukemia virus-encoded antigens. J Exp Med (1989) 169(2):457-67. doi:10.1084/jem.169.2.457

39. Donnarumma T, Young GR, Merkenschlager J, Eksmond U, Bongard N, Nutt SL, et al. Opposing development of cytotoxic and follicular helper CD4 T cells controlled by the TCF-1-Bcl6 Nexus. Cell Rep (2016) 17(6):1571-83. doi:10.1016/j.celrep.2016.10.013

40. Duley AK, Ploquin MJ, Eksmond U, Ammann CG, Messer RJ, Myers L, et al. Negative impact of IFN-gamma on early host immune responses to retroviral infection. J Immunol (2012) 189(5):2521-9. doi:10.4049/jimmunol.1201125

41. Merkenschlager J, Ploquin MJ, Eksmond U, Andargachew R, Thorborn G, Filby A, et al. Stepwise B-cell-dependent expansion of $\mathrm{T}$ helper clonotypes diversifies the T-cell response. Nat Commun (2016) 7:10281. doi:10.1038/ ncomms 10281

42. Ploquin MJ, Eksmond U, Kassiotis G. B cells and TCR avidity determine distinct functions of CD4+ T cells in retroviral infection. J Immunol (2011) 187(6):3321-30. doi:10.4049/jimmunol.1101006

43. Marshall HD, Chandele A, Jung YW, Meng H, Poholek AC, Parish IA, et al. Differential expression of Ly6C and T-bet distinguish effector and memory Th1 CD4(+) cell properties during viral infection. Immunity (2011) 35(4):633-46. doi:10.1016/j.immuni.2011.08.016

44. Crotty S. Do memory CD4 T cells keep their cell-type programming: plasticity versus fate commitment? Complexities of interpretation due to the heterogeneity of memory CD4 T cells, including T follicular helper cells. Cold Spring Harb Perspect Biol (2018) 10(3):a032102. doi:10.1101/cshperspect.a032102

45. Choi YS, Yang JA, Yusuf I, Johnston RJ, Greenbaum J, Peters B, et al. Bcl6 expressing follicular helper CD4 T cells are fate committed early and have the capacity to form memory. J Immunol (2013) 190(8):4014-26. doi:10.4049/ jimmunol.1202963 
46. Young GR, Ploquin MJ, Eksmond U, Wadwa M, Stoye JP, Kassiotis G. Negative selection by an endogenous retrovirus promotes a higher-avidity CD4+ T cell response to retroviral infection. PLoS Pathog (2012) 8(5):e1002709. doi:10.1371/journal.ppat.1002709

47. Bayer W, Tenbusch M, Lietz R, Johrden L, Schimmer S, Uberla K, et al. Vaccination with an adenoviral vector that encodes and displays a retroviral antigen induces improved neutralizing antibody and CD4+ T-cell responses and confers enhanced protection. J Virol (2010) 84(4):1967-76. doi:10.1128/ JVI.01840-09

48. Fazilleau N, Mcheyzer-Williams LJ, Rosen H, Mcheyzer-Williams MG. The function of follicular helper T cells is regulated by the strength of $\mathrm{T}$ cell antigen receptor binding. Nat Immunol (2009) 10(4):375-84. doi:10.1038/ni.1704

49. Nurieva RI, Podd A, Chen Y, Alekseev AM, Yu M, Qi X, et al. STAT5 protein negatively regulates $\mathrm{T}$ follicular helper (Tfh) cell generation and function. J Biol Chem (2012) 287(14):11234-9. doi:10.1074/jbc.M111.324046

50. Lanzavecchia A, Sallusto F. Antigen decoding by T lymphocytes: from synapses to fate determination. Nat Immunol (2001) 2(6):487-92. doi:10.1038/88678

51. Anderson AC, Joller N, Kuchroo VK. Lag-3, Tim-3, and TIGIT: co-inhibitory receptors with specialized functions in immune regulation. Immunity (2016) 44(5):989-1004. doi:10.1016/j.immuni.2016.05.001

52. Andrews LP, Marciscano AE, Drake CG, Vignali DA. LAG3 (CD223) as a cancer immunotherapy target. Immunol Rev (2017) 276(1):80-96. doi:10.1111/ imr.12519
53. Butler NS, Moebius J, Pewe LL, Traore B, Doumbo OK, Tygrett LT, et al. Therapeutic blockade of PD-L1 and LAG-3 rapidly clears established bloodstage Plasmodium infection. Nat Immunol (2011) 13(2):188-95. doi:10.1038/ ni. 2180

54. Han S, Asoyan A, Rabenstein H, Nakano N, Obst R. Role of antigen persistence and dose for CD4+ T-cell exhaustion and recovery. Proc Natl Acad Sci U S A (2010) 107(47):20453-8. doi:10.1073/pnas.1008437107

55. Knoechel B, Lohr J, Kahn E, Abbas AK. The link between lymphocyte deficiency and autoimmunity: roles of endogenous $\mathrm{T}$ and B lymphocytes in tolerance. J Immunol (2005) 175(1):21-6. doi:10.4049/jimmunol.175.1.21

Conflict of Interest Statement: The authors declare that the research was conducted in the absence of any commercial or financial relationships that could be construed as a potential conflict of interest.

Copyright (c) 2018 Danelli, Donnarumma and Kassiotis. This is an open-access article distributed under the terms of the Creative Commons Attribution License (CC BY). The use, distribution or reproduction in other forums is permitted, provided the original author(s) and the copyright owner are credited and that the original publication in this journal is cited, in accordance with accepted academic practice. No use, distribution or reproduction is permitted which does not comply with these terms. 